\title{
Epochenwechsel in China - mit Goethe: Guo Moruo, Richard Wilhelm und die Bewegung des 4. Mai 1919
}

„Der Edle pflegt die Wurzel; steht die Wurzel fest, so wächst der Weg. Pietät und Gehorsam: das sind die Wurzeln des Menschentums.“

Konfuzius: Gespräche $e^{1}$

\author{
„Bis zur Wurzel glühn die hohlen \\ Stämme, Purpurrot im Glühn. - \\ Was sich sonst dem Blick empfohlen, \\ Mit Jahrhunderten ist hin.“ \\ Goethe: Faust ${ }^{2}$
}

\section{Faust-Lektüre in der chinesischen Provinz: Goethe-Spuren}

Anlässlich des „Jugendtages“, der in China in Erinnerung an den 4. Mai 1919 alljährlich begangen wird, erzählte der chinesische Präsident Xi Jinping am 4. Mai 2013 im Gespräch mit Vertretern chinesischer Jugendorganisationen von jener Epoche seines Lebens, die er während der maoistischen Kulturrevolution Ende der sechziger und zu Beginn der siebziger Jahre des 20. Jahrhunderts bei einer landwirtschaftlichen Produktionsbrigade in der Provinz Shaanxi verbracht hat. Goethes Faust, so berichtet der Präsident bei dieser Gelegenheit, habe zu den Büchern gezählt, die er damals in der örtlichen Bibliothek entliehen und - dreimal! gelesen habe. Um die für die wiederholte Lektüre des umfangreichen Textes nötige Verlängerung der eigentlich strikt begrenzten Leihfrist zu erlangen, habe er den Bibliothekar mehrmals zu einer Eierspeise eingeladen. Das ist angesichts der in jenen Jahren notorisch prekären Versorgungslage sicherlich eine außergewöhnlich hohe „Leihgebühr“, die uns auf die große Bedeutung schließen lässt,

1 Aus dem Lehrsatz über die „Ehrfurcht als Grundlage der staatlichen Ordnung“. Konfuzius 2018 [1910], 67.

2 Goethes Faust wird mit Angabe der Verszahlen zitiert nach Goethe 2017, hier V. 11334-1137.

๖ Open Access. @ 2021 Michael Jaeger, publiziert von De Gruyter. (cc) BY-NC-ND Dieses Werk ist lizensiert unter einer Creative Commons Namensnennung - Nicht-kommerziell - Keine Bearbeitung 4.0 International Lizenz. https://doi.org/10.1515/9783110682427-008 
die die Faust-Lektüre für den Studenten Xi Jinping besaß. Und offenbar ist in den Augen des Staatspräsidenten Xi Jinping die Erinnerung an sein Faust-Studium ein Motiv, das sich nun gerade in die Retrospektive auf den 4. Mai 1919 passend einfügt und dessen Bedeutung für die chinesische Geschichte erhellt.

Im erweiterten historischen Rückblick auf das chinesische 20. Jahrhundert stellt sich allerdings die Frage: Wie konnte mitten in der Kulturrevolution, die ja nicht nur die klassische Überlieferung Chinas, sondern erst recht die westliche Literatur verteufelte, der in die landwirtschaftliche Produktion geschickte Student Xi Jinping in einer Provinzbibliothek an eine chinesische Fassung von Goethes Faust gelangen? Bei dem Buch, das er dreimal hintereinander verschlang, handelte es sich zweifellos um die Übersetzungen, die Guo Moruo über mehrere Jahrzehnte hinweg erarbeitet hatte. Bereits 1928 war Faust I erschienen, 1947 folgte die Übersetzung von Faust II, die 1953 wiederaufgelegt wurde. ${ }^{3}$

Den Spuren von Guos Faust-Übersetzung nachgehend, gelangen wir zu jener bemerkenswerten Goethe-Rezeption, die im Umkreis der 4.-Mai-Bewegung und ihres Interesses für die europäische und amerikanische Literatur einsetzt. Goethe nimmt in dieser Perspektive die Gestalt eines Repräsentanten der westlichen Kultur an, deren Autonomie-, Emanzipations- und Fortschrittsideale die literarische Revolution in China, ihren Protest vor allem gegen die konfuzianisch geprägte Tradition und schließlich Chinas Weg in die Moderne beflügeln sollten. Die im 20. Jahrhundert paradox verlaufende chinesisch-deutsche Ideengeschichte kommt prägnant zu Gesicht, wenn man vergleichend auf jene Rezeption der klassischen Literatur des Konfuzianismus und Daoismus schaut, die zur selben Zeit in Deutschland anhebt, um hier nun allerdings die Kritik der Moderne und ihrer Fortschritts- und Rationalisierungsideale $\mathrm{zu}$ inspirieren. Das Interesse an der chinesischen Philosophie und Literatur begleitete das im Vorfeld des Ersten Weltkriegs und dann erst recht nach der deutschen Niederlage anschwellende Krisenbewusstsein. Der bedeutendste und wirkungsmächtigste Protagonist der deutschen China-Faszination dieser Epoche war Richard Wilhelm. Aus China, wo er von 1899 bis 1920 und 1922 bis 1924 als Missionar und Sinologe arbeitete, versorgte er das deutsche Publikum mit den Übersetzungen der Klassiker der chinesischen Philosophie und Literatur. Daneben war Wilhelm in China als Vermittler der deutschen Kultur tätig, nicht zuletzt als Dozent der Peking Universität - also gleichsam im intellektuellen Zentrum der chinesischen Reformdebatte -, an der er in den Jahren zwischen 1922 und 1924 eine Goethe- und Faustvorlesung hielt.

3 Vgl. Wuneng (2000, 56-60) zur Situation des chinesischen Buchmarkts, auf dem nach 1949 und erst recht während der Kulturrevolution (1966-1976) - nur die im chinesischen Staatsverlag erschienenen Goethe-Übersetzungen Guo Moruos greifbar waren. 


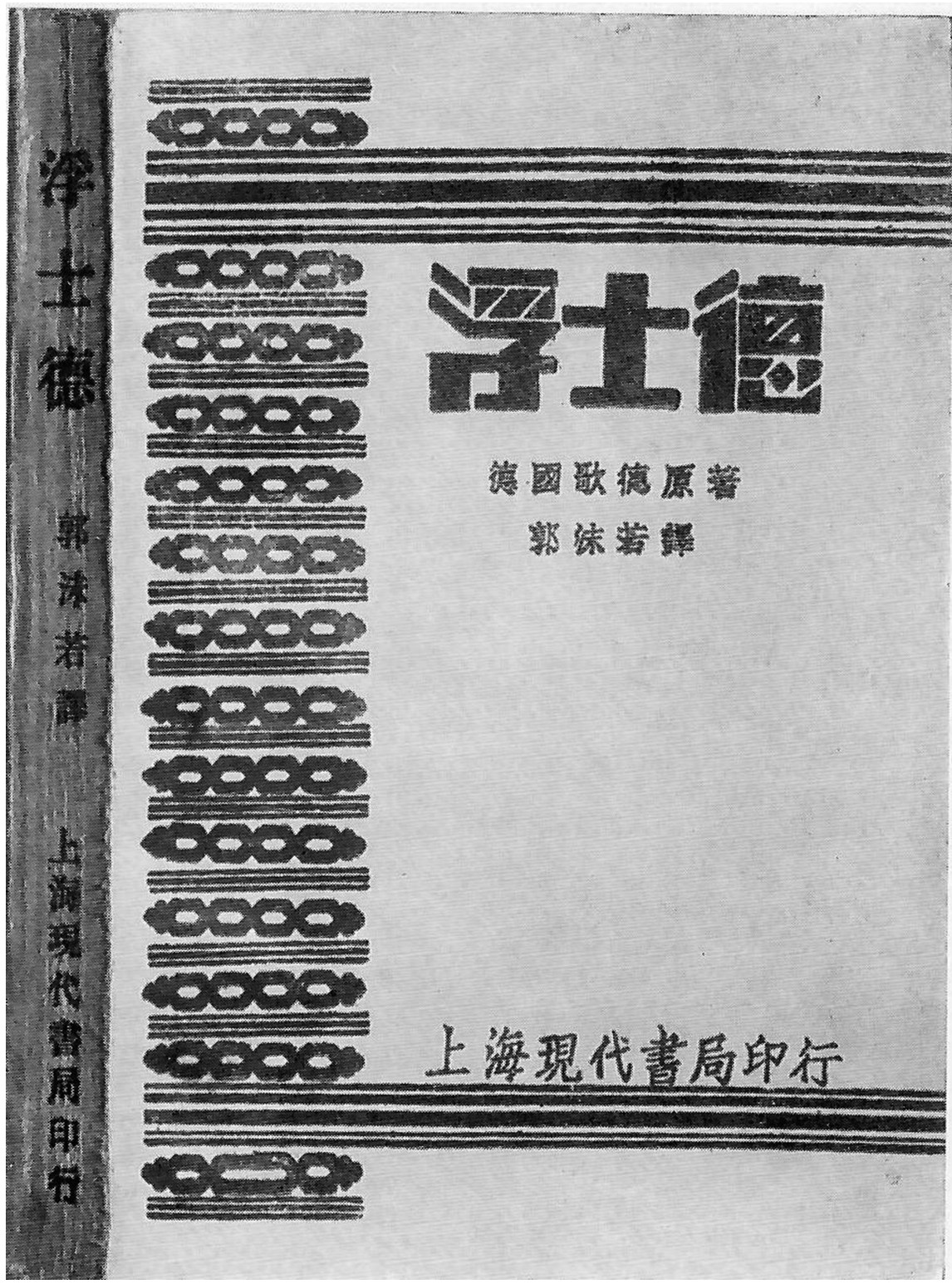

Abb. 1: Buchumschlag der Faustübersetzung (Faust I) von Guo Moruo, Shanghai 1930.

Das in deutscher Sprache geschriebene maschinenschriftliche Manuskript zu Wilhelms Lehrveranstaltung hat sich in den Bibliotheksarchiven erhalten, wo ich es während eines Gastsemesters an der Peking Universität im Jahre 2018 
einsehen konnte. Es wird sich im Folgenden zeigen, dass Wilhelms Text verstanden werden kann als Beitrag zur zeitgenössischen Goethe-Rezeption in China und als subtile Kritik an der die chinesischen Werther- und Faust-Lektüren kennzeichnenden Begeisterung für die prometheisch-titanische Rebellion der goetheschen Sturm-und-Drang-Helden.

Gleichsam im philologischen Brennglas wird die Gegenüberstellung der von Guo Moruo und Richard Wilhelm denkbar unterschiedlich ausgestalteten Thematik „Goethe und China“ den Blick öffnen auf den widerspruchsvollen Ideenaustausch zwischen China und Deutschland in der Zeit der 4.-Mai-Bewegung. Auffällig sind die übereinstimmenden zeitgeschichtlichen Parameter dieser intellektuellen chinesisch-deutschen Koinzidenz im Zeichen Goethes: Zeigt sich auf exemplarische Weise in Guo Moruos Werk die traditionskritische Revolte, die nach dem Zusammenbruch der Mandschu-Dynastie und nach der Abdankung des chinesischen Kaiserhauses eingeht in die Modernisierungsprogrammatik der 4.-Mai-Bewegung, so wird man auf der anderen Seite Richard Wilhelms chinesisch-deutscher Vermittlungs- und Übersetzungsarbeit jene Modernismus- und Rationalismuskritik ansehen können, die in Deutschland nach der Erfahrung des Ersten Weltkriegs und nach dem Zusammenbruch des deutschen Kaiserreichs Intellektuellen- und Avantgardekreise unterschiedlichster Couleur erfasst hatte.

\section{Guo Moruo}

Wenden wir uns zunächst dem Faust-Übersetzer Guo Moruo zu, dessen Biografie die Brüche, Abgründe und Kontinuitäten des chinesischen 20. Jahrhunderts abbildet. Geboren 1892 in der Spätzeit der Mandschu-Dynastie, durchlief Guo zunächst noch das alte Bildungssystem der überlieferten Gelehrsamkeit. ${ }^{4}$ Später sehen wir Guo Moruo, wie zahlreiche seiner Altersgenossen, Lu Xun etwa, 1913 auf dem Weg zum Medizinstudium nach Japan. ${ }^{5}$ Nach Japan ist Guo Moruo wohl auch deshalb gegangen, weil er auf diese Weise einer Ehe entlaufen

\footnotetext{
4 Über den das Ende der Qing-Dynastie kennzeichnenden Niedergang des traditionellen chinesischen Schulwesens, in dessen Zentrum das Studium - und Auswendiglernen - der Klassiker stand, berichtet Guo Moruo in seinen Jugenderinnerungen (Guo 1985b, hier insbesondere im ersten Text Zeit der Revolution [urspr. 1929], 24-39).

5 Seine Jugenderinnerungen lässt Guo Moruo im Jahre 1913 gleichsam symbolisch enden mit dem Abschied aus China - wo unterdessen Yuan Shikai Präsident der noch jungen Republik geworden war und eine restaurative Politik verfolgte - sowie mit dem Aufbruch zum Studium in der modernen Welt Japans (Guo 1985b, 242-257).
} 


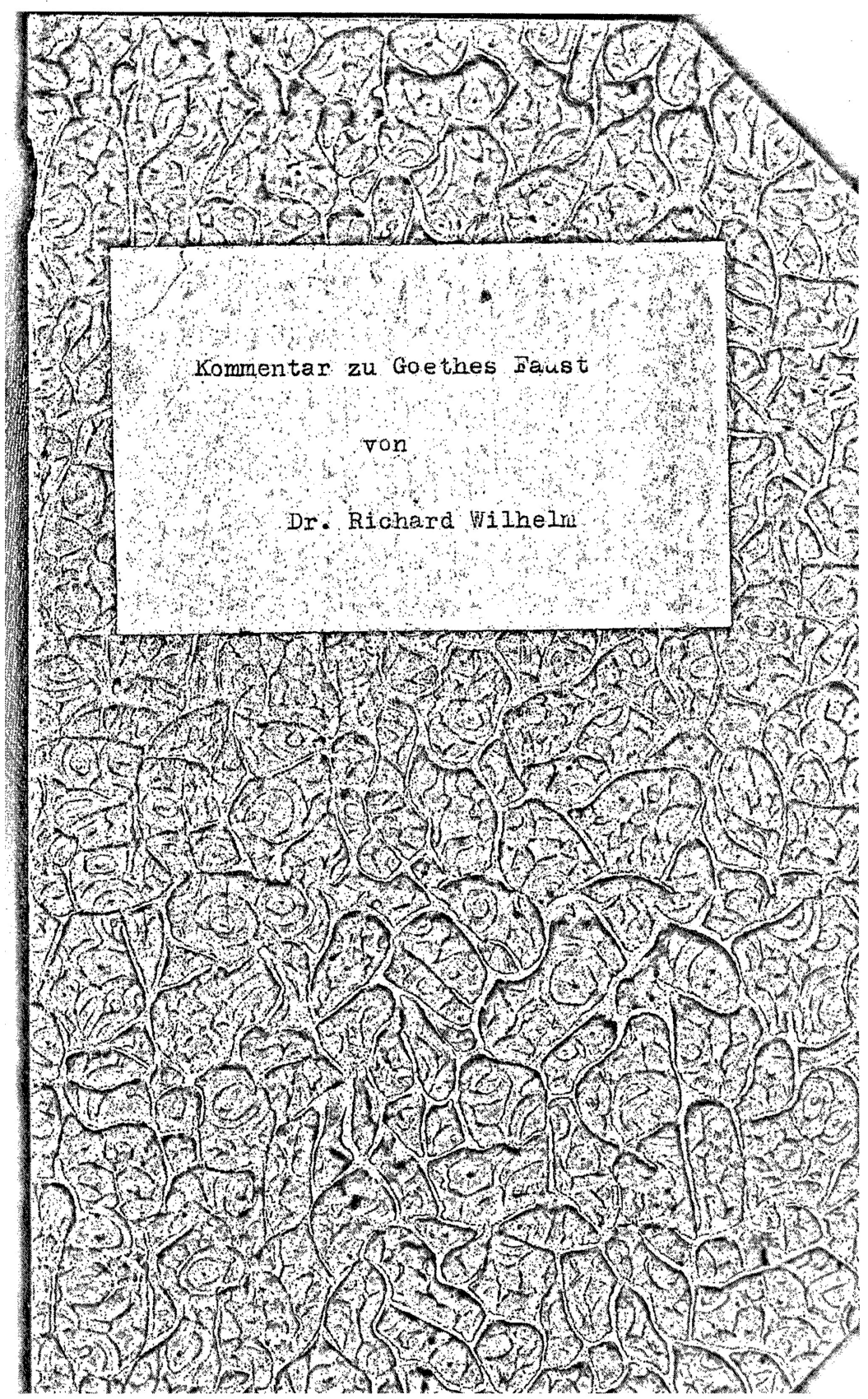

Abb. 2: Titelblatt des Faustkommentars von Richard Wilhelm. Maschinenschriftliches Manuskript in der Universitätsbibliothek der Peking Universität. 
konnte, die seine Eltern für ihn arrangiert hatten. Das ist keineswegs ein individuelles biografisches Detail am Rande, vielmehr wird der Protest gegen das im alten, konfuzianisch geprägten China verbreitete Phänomen der arrangierten Ehe später zu einem der markanten Motive der Revolution des 4. Mai 1919 und ihrer Literatur zählen. ${ }^{6}$

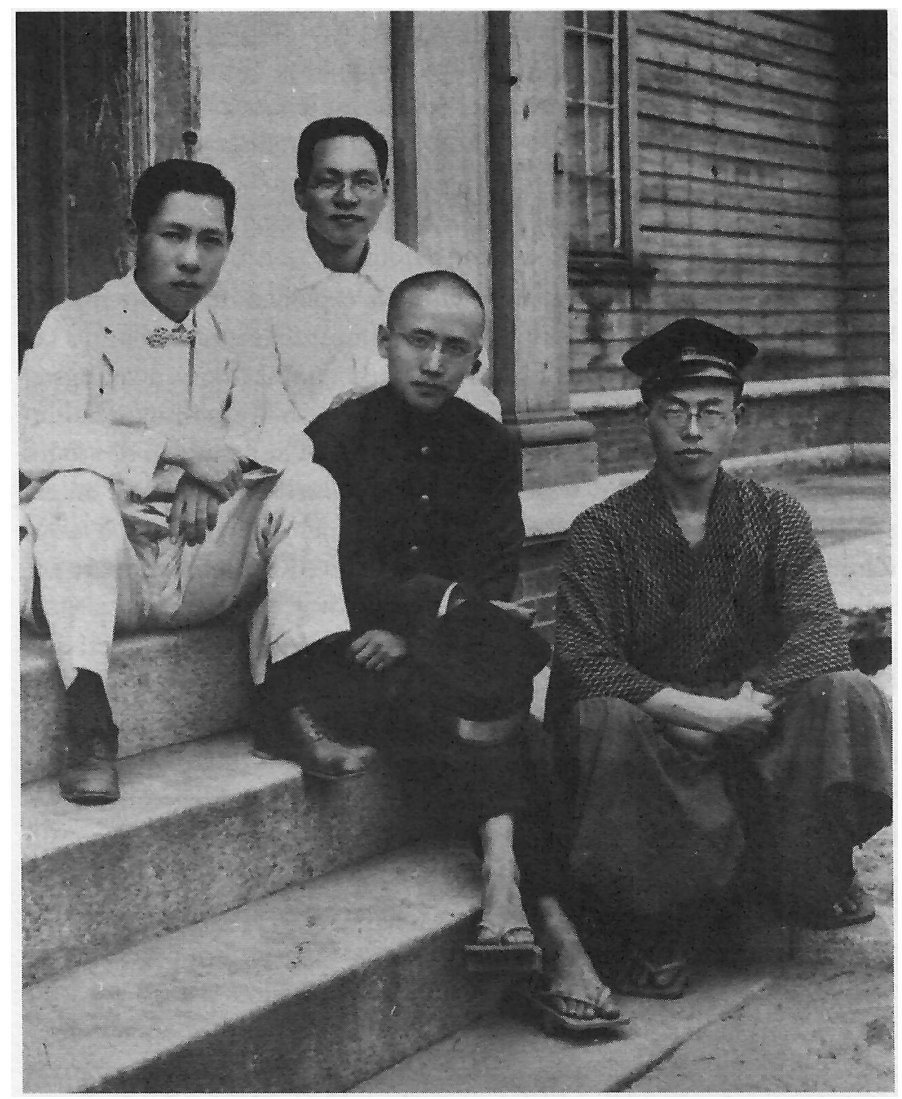

Abb. 3: Guo Moruo (zweiter von rechts) beim Medizinstudium in Japan.

6 Als absurdes Theater einer völlig sinnentleerten und gleichwohl rigiden Tradition schildert Guo Moruo - in einem „Leidensbericht“ - die Zeremonie der von seiner Familie für ihn arrangierten Hochzeit mit einer ihm bis zu diesem Zeitpunkt völlig unbekannten Frau, die er nach Abschluss des sich über mehrere Tage hinziehenden grotesken Rituals sofort wieder verlässt (Guo 1985b, 165-184, hier 184). 
In Japan studiert Guo Moruo Medizin, sein Interesse gilt aber vor allem dem Fremdsprachenstudium und der Lektüre europäischer und amerikanischer Literatur. Er ist mit Übersetzungen ins Chinesische befasst und schreibt Gedichte, gründet mit literarisch gleichgesinnten chinesischen Studenten in Japan die „Schöpfungs-Gesellschaft“, deren ästhetisches Programm es ist, die chinesische Umgangs- und Alltagssprache auch für die lyrische Produktion zu verwenden.

Mit dieser literarischen Unternehmung geraten Guo Moruo und seine Freunde in unmittelbare Nähe jener traditionskritischen Intellektuellen, die sich seit Beginn des 20. Jahrhunderts an der neugegründeten Peking Universität gesammelt hatten und die angesichts der militärischen und politischen Demütigungen, die das alte kaiserliche China in der Auseinandersetzung mit den Kolonialmächten und insbesondere im Konflikt mit Japan erfahren hatte, eine fundamentale politische und kulturelle Modernisierung Chinas forderten.

\subsection{Guo Moruo und Goethe}

Wie bei Lu Xun, so sind auch in den Schriften Guo Moruos die Befreiung des Individuums und die Rebellion gegen die Fesseln der Überlieferung die zeittypischen Hauptthemen. Das dazu passende beispielgebende literarische Emanzipationsprogramm findet Guo in Goethes Texten der Sturm-und-Drang-Periode, die er bei seinen Literaturstudien in Japan kennengelernt hatte. Goethes Aktualität im Kontext des kulturpolitischen Programms des 4. Mai 1919 gewinnt einen deutlichen und prominenten Ausdruck in der 1920 unter dem Titel „Kleeblatt“ erscheinenden Briefsammlung, in der die Autoren Guo Moruo, Tian Han und Zong Baihua ihre Diskussionen über einen antitraditionalistischen Literaturbegriff im Allgemeinen und über ihre Goethe-Lektüre im Besonderen publizierten. Im Vorwort des Bandes erklärt Tian Han Goethe zum „Mittelpunkt“ der literarischen Debatte der drei Schriftsteller und verbindet mit der Veröffentlichung ihrer Korrespondenz gar die Hoffnung auf einen das junge Publikum in Begeisterung versetzenden chinesischen Werther-Effekt:

\footnotetext{
All diese Briefe von uns stehen in engem Zusammenhang miteinander, in einen Band aufgenommen ähneln sie den Leiden des jungen Werthers; nachdem Goethe sein Buch veröffentlicht hatte, entstand ein großes Wertherfieber in der deutschen Jugend! Nun erscheint unser Kleeblatt, und in der chinesischen Jugend muss ein großes Kleeblatt-Fieber entstehen!

(Zitiert nach Wuneng 2000, 31)
}

Die brisante Bedeutung vermag Goethes Werther in der Wahrnehmung der Kleeblatt-Autoren deshalb zu gewinnen, weil sie den Briefroman der deutschen Sturm-und-Drang-Epoche des 18. Jahrhunderts als programmatische Rebellion 
des empfindsamen und zugleich selbstbewussten Subjekts gegen die Fesseln der Tradition verstehen und weil sie - so ihr nicht eben bescheidener Anspruch mit ihren eigenen Briefen die chinesische Jugend des 20. Jahrhunderts in eine enthusiastische Sturm-und-Drang-Bewegung zur Befreiung des individuellen Selbstbewusstseins versetzen wollen. Werther ist in dieser Perspektive das literaturgeschichtliche Symbol eines allgemeingültigen modernen Autonomiekonzepts, dessen Signalwort „Ich“ lautet.

So kann Goethe im Kontext des 4. Mai 1919 und der Neue-Kultur-Bewegung zum Stichwortgeber einer neuen Ästhetik im Zeichen der revoltierenden Subjektivität werden, wie es Guo Moruo in der Kleeblatt-Korrespondenz erläutert: „Ich denke, dass wir die Werke von Goethe so viel wie möglich übersetzen und erforschen müssen, da seine Zeit - die Zeit des Sturm und Drang - unserer Zeit sehr ähnlich ist! Von ihm können wir viel lernen!“ (zitiert nach Wuneng 2000, 34). An das hier präsentierte Arbeitsprogramm sollte sich Guo Moruo selbst während der folgenden Jahre genau halten. Denn bereits vor seinen Übertragungen des Faustdramas hatte er 1922 eine Übersetzung von Goethes Werther veröffentlicht, wie sich das für die Vertreter der Neue-Kultur-Bewegung gehört, in chinesischer Umgangssprache und womöglich gerade deshalb mit gewaltigem Erfolg beim chinesischen Publikum (vgl. Wuneng 2000, 37-38).

Die Pathosfiguren der goetheschen Sturm-und-Drang-Texte, neben Werther und Faust vor allem Prometheus, hört man denn auch im Hintergrund gleichsam mitsprechen in Guo Moruos eigener Dichtung, besonders deutlich in seiner 1921 erscheinenden Gedichtsammlung Göttinnen, darin er unter dem Titel „Himmelshund“ eine Hymne anstimmt auf das alle Grenzen der Tradition durchbrechende moderne autonome Subjekt. Man wird dieses Gedicht als lyrisches Manifest der Neue-Kultur-Bewegung ansehen können. Jede der 29 Verszeilen setzt mit „Ich“ ein und protestiert solchermaßen gegen das Aufgehen des individuellen Selbstbewusstseins in der streng hierarchisch gegliederten kosmischen, politisch-gesellschaftlichen und familiär-patriarchalischen Ordnung, wie es bislang für die vom konfuzianischen Denken geprägte chinesische Dichtung typisch war. Guo Moruos vom jungen Goethe inspirierter Prometheismus lässt nun das Ich vorrücken ins Zentrum des Universums:

Ich bin ein Himmelshund!/Ich verzehre den Mond,/Ich verzehre die Sonne,/Ich verzehre alle Sterne,/Ich verzehre das gesamte Universum./Ich bin ich!//Ich bin das Mondlicht/Ich bin das Sonnenlicht,/Ich bin das Licht aller Sterne,/Ich bin das Licht der Röntgenstrahlen,/Ich bin die Gesamtheit aller Energy des Universums!

$\left(\right.$ Guo 1985a, 35) ${ }^{7}$

$7 \mathrm{Zu}$ den Spuren der Goethe-Rezeption in Guo Moruos Gedichtband Göttinnen, insbesondere zu den Faust- und Prometheusbezügen darin, vgl. Schäfer 1986. 
Das chinesische Original - naturgemäß in Umgangssprache geschrieben nimmt die englischen Wörter „X-ray“ (für Röntgenstrahlen) und „energy“ in den poetischen Text auf und bildet auf diese Weise das prometheische Bündnis von revoltierendem Voluntarismus und technischer Innovation ab. Unter den Bedingungen der Moderne vollzieht sich Prometheus’ Auflehnung gegen das religiöse Fundament der überlieferten Kultur als industrielle Revolution. Sie treibt den Prozess gegen die Tradition an und vollzieht den Raub des himmlischen Feuers - gleichgültig, ob es von den Göttern des Westens oder des Ostens gehütet wird - seit Beginn des 20. Jahrhunderts in globalen Dimensionen. Daher kann es in Guo Moruos Gedicht heißen: „Ich brenne wie das Feuer!/Ich schreie wie das Meer!/Ich rase wie die Elektrizität“ (Guo 1985a, 35). In solchen in der chinesischen Lyrik bislang unerhörten Proklamationen einer rebellischen Subjektivität gewinnen die beiden Seiten der Bewegung des 4. Mai einen literarischen Ausdruck: die Konzepte einer modernen Ästhetik sowie die Ideen der gesellschaftlichen und ökonomischen Modernisierung.

Den subjektiven und den objektiven Aspekt dieser spezifisch modernen Revolte gegen die konfuzianischen Fundamente des alten China spricht Guo Moruo auch im „Prolog“ zu seiner Anthologie Göttinnen aus. Die Gedichte der jetzt anbrechenden Epoche sind nämlich als jene sehr weltlichen „Göttinnen“ anzusehen, mit deren Hilfe die Emanzipation sowohl des individuellen Gefühlslebens - des „Herzens“, wie es empfindsamkeits- und Sturm-und-Drang-typisch heißen muss - wie auch der rationalen Erkenntnis aus dem überlieferten Korsett der Verhaltens- und Denkmuster gelingen soll: „Göttinnen!/Geht und sucht Menschen, die beben wie ich;/Geht und sucht Menschen, die brennen wie ich./Geht und rührt meiner Generation/Die Stränge des Herzens auf,/Entflammt ihr Wissenslicht!“( Guo 1985a, 34).

Phantastisch mutet vorerst noch die Verbindung an, die Guo Moruo in der ersten Strophe des „Prologs“ herstellt zwischen dem emotionalen Beben, das die neue Poesie des autonomen Subjekts unter der jungen Generation Chinas auslösen soll, und dem kommunistischen Modernisierungsprogramm einer vergesellschafteten Ökonomie. Zwar werden in Guos Gedicht schon alle Schlüsselbegriffe der marxistischen Doktrin genannt - Privatbesitz, Eigentum, Arbeit, Produktion, Proletariat -, allerdings handelt es sich bei dem Produktionsprozess, von dem hier die Rede ist, um Poesie: „Ich bin ein Proletarier./Denn außer meinem splitternackten Ich/Verfüge ich über keinen Privatbesitz./Die, Göttinnen“ sind das Produkt meiner Arbeit,/Also sind sie mein Eigentum,/Aber ich will Kommunist sein/Und sie öffentlich machen“ (Guo 1985a, 34). Dieses Bündnis aus einem zunächst noch poetisch verstandenen Kommunismus und der Ästhetik des expressionistisch-lyrischen Subjektivismus, wofür Guo Moruos „Göttinnen“ einstehen, sollte sich wenig später auf dem Weg Guo Moruos in 
die Orthodoxie des chinesischen Marxismus wieder auflösen. Nicht Werther, sondern Faust wird dann sein aus dem Werk Goethes stammender literarischer Begleiter sein.

\subsection{Guo Moruos Karriere}

Guo Moruo hatte, mit Unterbrechungen, über dreißig Jahre an seiner FaustÜbersetzung gearbeitet, etwa zwischen 1920 und 1950, also in der Ära des gewaltigen Umbruchs in China, der von endlosen Kriegen und Bürgerkriegen begleitet war, an denen sich Guo Moruo in wechselnden Positionen und in unterschiedlichen politischen Konstellationen beteiligte, denen er zeitweise aber auch ins Exil nach Japan und Hongkong auswich. Wie so viele Aktivisten des 4. Mai wandte sich Guo Moruo Mitte der 1920er Jahre dem Marxismus zu und nahm auf Seiten der kommunistischen Partei 1925 während der Einheitsfront von Nationalisten (GMD) und Kommunisten (KPCh) am Feldzug gegen die Warlords teil. Als die Einheitsfront zerbricht und 1927 die Kommunistenverfolgungen durch den Guomindang-Führer Chiang Kai-shek beginnen, geht Guo Moruo für die nächsten zehn Jahre nach Japan, ehe er 1937 mit Ausbruch des Japanisch-Chinesischen Kriegs nach China zurückkehrt, wo er in der neuerdings wieder geschlossenen Einheitsfront von Guomindang und Kommunisten eine Propagandaabteilung leitet. Nach dem abermaligen Zerbrechen dieses Bündnisses weicht Guo Moruo nach Hongkong aus, ehe er sich schließlich während des nach 1945 mit unerbittlicher Härte zwischen Guomindang und Kommunisten ausbrechenden Bürgerkriegs Mao Zedongs roter Armee anschließt.

Bei Maos Ausrufung der Volksrepublik vom Tor des himmlischen Friedens vor dem alten Kaiserpalast in Peking am 1. Oktober 1949 ist Guo mit dabei unter den führenden Kadern der KPCh. Es beginnt zunächst eine steile Karriere in Staat und Partei, Guo ist der parteioffizielle Intellektuelle und Schriftsteller schlechthin, 1949 stellvertretender Ministerpräsident, 1954 stellvertretender Vorsitzender des Nationalen Volkskongresses. 1966, mit Beginn der Kulturrevolution, folgt, wie bei so vielen Intellektuellen der Partei, der jähe Absturz. Daran schließt sich an das zeittypische Schauspiel des Gesichtsverlusts und der Versuche, das Gesicht wiederzugewinnen, einerseits durch öffentliche Schuldbekenntnisse und Denunziation, andererseits durch bedingungslose Zustimmung zum Prinzip der Kulturrevolution, also zum kompromisslosen Kampf gegen die „vier Alten“ der chinesischen Überlieferung: gegen „alte Ideen, alte Kultur, alte Sitten, alte Praktiken“ (Dabringhaus 2008, 93). Diesem Prinzip des radikalen Traditionsbruchs sind dann während der Kulturrevolution auch die verhängnisvollen Zerstörungen der alten chinesischen Kultur (ihrer Tempelge- 
bäude vor allem) geschuldet, deren Spuren bis zu diesem Zeitpunkt noch allgegenwärtig in den Städten und auf dem Lande sowie im privaten Raum der chinesischen Familien waren. So bringt das Prinzip „Kulturrevolution“, das die moderne chinesische Geschichte kennzeichnet, die 4.-Mai-Bewegung, wie Sabine Dabringhaus erläutert, in eine höchst paradoxe Verbindung zu den Ereignissen der sechziger Jahre des 20. Jahrhunderts:

Nichts [so das radikale Programm der Kulturrevolution] sollte mehr an die Vergangenheit erinnern. Hatte der Ikonoklasmus der Vierten-Mai-Ära zu einer Öffnung Chinas für alles Neue, Moderne, Westliche geführt, so engten sich die Kulturrevolutionäre der 1960er Jahre ganz auf eine maoistische Orthodoxie ein.

(Dabringhaus 2008, 93)

Indem Guo komplett auf die neue Parteilinie einschwenkt, Lobgedichte auf die Kulturrevolution verfasst, gelingt es ihm zwar, sein Gesicht wiederzugewinnen, seine Familie schützen kann er indessen nicht. Zwei seiner Söhne verlieren ihr Leben. 1969 erfolgt Guos Rehabilitierung.

Abermals beginnt ein steiler Aufstieg in einflussreiche Positionen, er rückt sogleich ins Zentralkomitee der KPCh auf, gehört zur privilegierten Parteiaristokratie, wohnt in Peking in einer renovierten Prinzenresidenz, steht als Präsident an der Spitze der chinesischen Akademie der Wissenschaften und ist der bevorzugte Gesprächspartner des alten Mao. Nach dessen Tod 1976 und dem Ende der Kulturrevolution finden wir Guo dann sogleich auf der Seite der Kritiker der ultralinken sogenannten „Vierer-Bande“ wieder. Am Ende seines Lebens wird Guo gefeiert als ein „Goethe Chinas“. Bei Guos Beerdigung 1978 hält der neue starke Mann der Partei, Deng Xiaoping, die Grabrede, derselbe Deng, der wenige Monate später die Reformen und die Öffnung Chinas und mithin das Ende der Epoche Maos einleitet. ${ }^{9}$

8 Zur Kultur als zentraler Schauplatz des Modernisierungs- und Revolutionsprozesses in der Geschichte Chinas seit der Mitte des 19. Jahrhunderts bemerkt Helwig Schmidt-Glintzer: „Allen chinesischen Modernisierungsbestrebungen seit der sogenannten Selbststärkungsbewegung im späten 19. Jahrhundert bis heute aber ist gemeinsam, dass sie die Modernisierung Chinas als eine Frage der Kultur behandeln. Zwar wurde von vielen die Auffassung vertreten, aus dem Westen sollte man nur Technik und Wissenschaft übernehmen (yong), in der Substanz (ti) aber chinesisch bleiben, doch sahen auch die Vertreter dieser These in der traditionellen Bildung und Sozialverfassung, kurz: im Konfuzianismus ein Hindernis für die Modernisierung“ (Schmidt-Glintzer 2008, 175).

9 Die Angaben zu Guo Moruos Karriere sind der Studie entnommen, die Pu Wang über den historischen Zusammenhang zwischen Guo Moruos Werk - mit der Übersetzung von Goethes Faust im Mittelpunkt - und der chinesischen Revolutionsepoche des 20. Jahrhunderts vorgelegt hat. $\mathrm{Pu}$ Wangs Interesse gilt dem politischen (,revolutionären“) Gehalt von Guos Übersetzungsarbeit (vgl. Wang 2018, 5). - In seiner speziellen, Literaturwissenschaft, Ideen-, Ideologie- und Zeitge- 


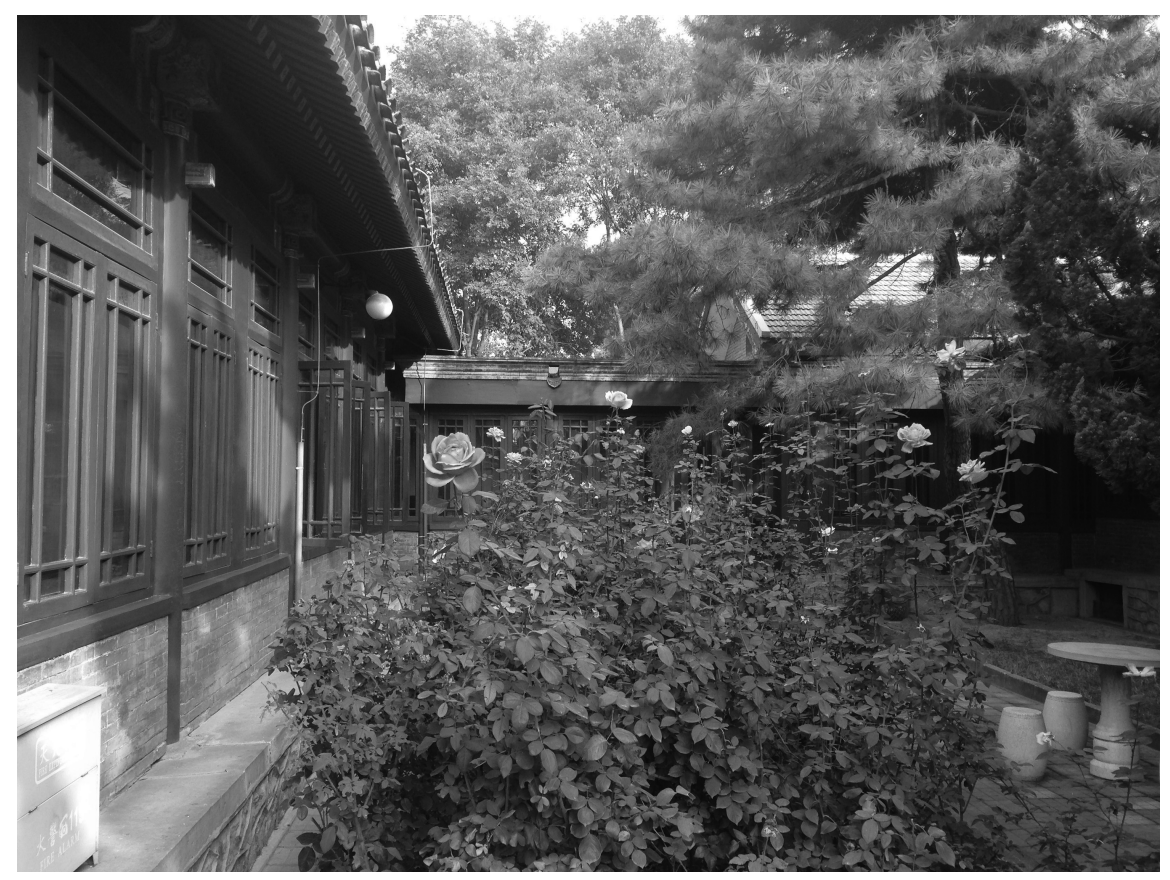

Abb. 4: Rosengarten in Guos Residenz in Peking.

\subsection{Faust und die moderne Geschichtsphilosophie}

Wenn man auf den gewaltigen Mahlstrom der Geschichte Chinas im 20. Jahrhundert schaut, fragt man sich verwundert, welchen Sinn, welche Erkenntnis nun ausgerechnet die Besinnung auf Goethe stiften soll in diesem riesenhaften historischen Drama, das über weite Strecken als epochale Tragödie verläuft und über ungezählte Opfer hinweggeht. Eine Antwort darauf gibt eine FaustReflexion Guos aus dem Jahre 1947, in der er mitten im chinesischen Bürger-

schichte verbindenden Fragestellung setzt Pu Wang die vorausgehende historische und politologische Forschung zur intellektuellen und politischen Biografie Guo Moruos fort. Dazu zählen insbesondere Roy 1971 und Chen 2007. - Diesseits von Pu Wangs revolutionsgeschichtlichen Ableitungen hat Nora Bartels am Beispiel von Fausts Eingangsmonolog in der Szene „Nacht“ die Faustübersetzung Guo Moruos einer übersetzungswissenschaftlichen Analyse - im Vergleich mit der japanischen Faustübersetzung von Mori Rintarō - unterzogen (vgl. insbesondere Bartels 2012, 115-137, zur Übersetzung Guos sowie zu Transkription und Rückübersetzung der chinesischen Fassung). 
krieg feststellt, dass Goethes Drama die Entwicklungsgeschichte des Zeitgeistes im europäischen 19. Jahrhundert darstelle, die für die gegenwärtige Revolution in China relevant sei, weil sich Goethes Tragödie ins chinesische 20. Jahrhundert übersetzen lasse. In der Geschichte, so Guos Überzeugung, sei es die des 19. Jahrhunderts (in Europa) oder die des 20. Jahrhunderts (in China), ist der gleiche produktive, sinnstiftende Geist tätig, und diesen substantiellen, in der Geschichte selbst gegenwärtigen und tätigen Geschichtssinn bringe Goethes Drama zur Anschauung. ${ }^{10}$

In Guos Perspektive ist die Übersetzung und das Verständnis des goetheschen Textes eine Erkenntnisübung, die befähigt zum richtigen Verständnis der Geschichte auch in China, die doch auf den ersten Blick so mahlstromhaft chaotisch aussieht, die aber doch produktiv ist, insofern sie, über alle Widersprüche, Leiden, Zerstörungen und Opfer hinweg, zuletzt immer eine sinnvolle Entwicklung ausführt, nach der Art einer kreativen Zerstörung, die man, wenn man es denn so will, etwa aus Mephistos Versen herauslesen kann: „Ich bin der Geist der stets verneint!/Und das mit Recht; denn alles was entsteht/Ist wert daß es zu Grunde geht“ (V. 1338-1340). Da jede Verneinung eine andere, neue Wirklichkeit erzeugt, lässt sich das von Mephisto gefeierte Zugrundegehen

10 Mithin, so die Generalthese von Pu Wang, ist es der Übersetzer Guo Moruo, der in seiner Übertragung der Fausttragödie Goethes in die chinesische Sprache zugleich den Nachweis einer Übertragbarkeit der marxistischen Geschichts- und Revolutionstheorie - also einer „Translatability of Revolution“ - auf die chinesische Politik im 20. Jahrhundert führt und der sich solchermaßen nun gerade in seiner literarischen Arbeit als (Faust-)Übersetzer an der chinesischen Revolution beteiligt: „[. . . [ in 1947, when the civil war between the GMD and the communists drew to a deadlock, he finished his translation auf Faust II. On that occasion, he characterized Goethe's epic drama as a ,developmental history of Zeitgeist` [shidai jingshen], and announced its relevance to the ongoing revolution, as if this German tragedy - an ,allegory of the nineteenth century - had been written for twentieth-century China“ (Wang 2018, 2). Und zusammenfassend stellt Pu Wang über die Guo Moruos Faustfaszination offenbar zugrundeliegende Verknüpfung von Übersetzung und Revolution fest: „Guo’s translation [. . . ] was inscribed in the Chinese Revolution. It is not only a linguistic, interpretative, and intellectual transference, it also distills the historical experience of revolution. If in the May Fourth Movement Guo's translation of geschäftiger Geist [in seiner Übersetzung von Faust I, V. 511] as ,creative spirit" represented an identification with a new creativity/collectivity, then the ,difficult figuring of Zeitgeist in 1947 testified to the Chinese Revolution as a dialectical translation of confusing temporalities into an urgent momentum of sociopolitical change“ (Wang 2018, 157). Zwischen der frühen Goethe-Begeisterung im Umfeld der 4.-Mai-Bewegung und der späteren „Übersetzung“ der Fausttragödie in ein literarisches Abbild des Revolutionsprozesses in China liegt in Guos intellektueller Biografie während der 1930er Jahre eine Phase der strengen GoetheKritik, die, desgleichen marxistisch inspiriert, den fehlenden „Klassenstandpunkt“ in Goethes Werk moniert. Zu dieser Unterbrechung der Goethe-Rezeption bei Guo vgl. Bauer 1972, 193-197, sowie Roy 1971, 93-99 und 134-139. 
alles Entstandenen in einen dramatischen bzw. historisch-dialektischen Prozess übersetzen, dessen Antriebskraft die Negation ist. Aus der bösen Kraft, die verneint und zerstört, kann daher „ein Teil von jener Kraft“ werden, die „stets das Gute schafft“ (V. 1336-1337), so dass, wie es im „Prolog im Himmel“ heißt, sogar der „Teufel“ mit-,,schaffen“ muss (V. 343), sofern denn nur der Gesamtprozess versöhnlich ausgeht oder - wie nun sicherlich in Goethes Fausttragödie - gar mit einer Erlösung endet.

Diese poetisch-mystische Versöhnung des opferheischenden Handlungsverlaufs in Goethes Tragödie wurde schon in Hegels Faustspekulation zu einem literarischen Modell des modernen Prozessdenkens, das seit dem ausgehenden 18. Jahrhundert die Weltgeschichte als Fortschritts- und Emanzipationsunternehmen und mithin als profane Erlösung auslegt, sei es als philosophisches Wahrheitsgeschehen und Bewusstseinsbefreiung (bei Hegel) oder als politische Emanzipation und Revolution (bei den Linkshegelianern) oder dann als Industrialisierungsprozess und Unterwerfung der Natur (bei Marx). In allen Variationen dieses Prozessgeschehens, ob nun idealistisch oder materialistisch, ist die Weltgeschichte das Weltgericht. Der Prozess läuft im doppelten Wortsinn ab, als Bewegung und Gerichtsverhandlung. Die Geschichte selbst agiert als letzte Instanz, vollstreckt das Urteil über Vergangenheit und Überlieferung und treibt die zielgerichtete, sinnvolle und fortschrittliche Bewegung in die Zukunft an.

Nahezu wörtlich übernimmt Guo Moruo jene marxistische Auslegung der Faustspekulation Hegels, die Georg Lukács 1940 in Moskau ausgearbeitet hatte. Entsprechend heißt es in Guos Kurzer Interpretation von Faust, einem maßgeblichen Text der zeitgenössischen chinesischen Goethe-Rezeption, der 1947 zeitgleich mit der ersten Publikation seiner Faust-II-Übersetzung erschienen war:

(Faust) is clothed in a medieval vestment, but what is inside is the fire of the modern man's insatiable impulse. It seems to be a contradiction, and this ostensible contradiction determines the immense heterogeneity (pangzaxing) within Faust. But we should not be shocked by the appearance of this immense heterogeneity . . . . (The murkiness) . . . is actually ... . a faithful record of the development of the age. So I venture to argue that this is a work of reality, not only filled with the appearances of reality, but also with the soul (hun) of reality. A macro-soul (da hun) of reality, that is, the Zeitgeist, embodies a wide variety of micro-souls of reality, i. e. individualities . . . . [Goethe] . . revealed the truth of the development of the world, and grasped this dialectical spirit. ${ }^{11}$

11 Zitiert nach Pu Wangs englischer Übersetzung der Faustinterpretation Guo Moruos (Wang 2018, 147). Pu Wang lässt es ausdrücklich offen, ob Guo Moruo die marxistischen Faustauslegungen von Georg Lukács kannte (vgl. Wang 2018, 148). Indessen gestattet Guos Wortwahl „macro-soul ( $d a$ hun) of reality“ und „micro-souls of reality, i. e. individualities“ - keinen Zweifel darüber, dass er eben genau jene Verbindung von Hegelianismus und Marxismus zitiert, die die Fauststudien von Lukács kennzeichnet. In ihnen heißt es: „So entsteht für Goethe 


\subsection{Konfuzianische Klassik und westliche Moderne}

Diese Deutung aber der Geschichte als Prozess - als Entwicklungs-, Emanzipations-, Fortschritts-, Rationalisierungs-, Industrialisierungsprozess usw. - wird man mit Karl Löwith als Grundoperation und Signatur einer spezifisch westlichen Moderne ansehen, insofern die moderne europäische Geschichtsphilosophie die alte biblische, jüdisch-christliche Heilsgeschichte säkularisiert und in ein profanes, in der Weltgeschichte und durch dieselbe sich realisierendes Fortschrittsgeschehen übersetzt. ${ }^{12}$ Weil aber Goethes Faust in der geschichtsphilosophischen Schule Europas, zumal in ihrer marxistischen Abteilung, stets als literarisches Modell des Fortschritts- und Modernisierungsprozesses angesehen wurde, musste dieser Text in den Augen Guo Moruos nun gerade im Horizont der 4.-Mai-Bewegung eine hochbrisante Faszinationskraft gewinnen. In Gestalt nämlich der Fausttragödie, sofern man sie denn nur hegelianisch oder später mit den Augen von Georg Lukács „perfektibilistisch“ als ein literarisches Abbild des modernen dialektischen und marxistischen Geschichtsbewusstseins liest, hat Guo die Überlieferungskritik des 4. Mai und der späteren chinesischen Revolution mit der schärfsten Munition ausgestattet, die die Ideengeschichte des Westens zu Beginn des 20. Jahrhunderts an die junge, gegen die eigene Tradition aufbegehrende Generation des Ostens weitergeben konnte: mit dem

wie für Hegel der unaufhaltsame Fortschritt der Menschengattung aus einer Kette von individuellen Tragödien; die Tragödien im Mikrokosmus des Individuums sind das Offenbarwerden des unaufhaltsamen Fortschritts im Makrokosmos der Gattung: dies ist das gemeinsame philosophische Moment im Faust und in der Phänomenologie des Geistes“ (Lukács 1947, 147). Der allgemeine Geschichtsprozess scheint in Lukács’ Perspektive überhaupt erst „vorwärts“getrieben zu werden zum „Fortschritt“ durch die persönlichen Tragödien auf der Ebene der Individuen: „Der Weg der Gattung ist untragisch, er führt aber durch unzählige, objektiv notwendige, individuelle Tragödien“, auf die Hegel wie Goethe ,in einer grossartigen Unsentimentalität“ sähe (Lukács 1947, 147). - Zwar wurden Lukács’ Fauststudien und Guo Moruos Faust-II-Übersetzung sowie seine Kurze Interpretation in demselben Jahr 1947 publiziert. Lukács hatte allerdings seine im Gewande der Faustdeutung ausgeführte Übertragung der auf individueller Ebene tragisch verlaufenden Geschichte - in seinem Fall in der Sowjetunion der stalinistischen Schauprozesse - in einen allgemeinen gesellschaftlichen Fortschritt bereits 1940 in Moskau abgeschlossen (vgl. Lukács 1947, 7 und 207). Von dort wird Lukács’ Schlüsseltext der marxistischen Tragödieninterpretation und der hegelianischen „Aufhebung“ der realiter tragisch erfahrenen Zeitgeschichte seinen Weg auf den verschlungenen Pfaden des internationalen Kommunismus nach China genommen haben.

12 Die moderne Geschichtsphilosophie (des Westens) - ihr Prozessprinzip insbesondere führt Karl Löwith (1983 [1949]) als säkularisierte Fassung des heilsgeschichtlichen Denkens zurück auf die christliche und jüdische Überlieferung. 
historischen Prozessdenken, das in dieser Gestalt in der chinesischen Philosophie bis zum Beginn des 20. Jahrhunderts weitgehend unbekannt war, pflegte man doch im konfuzianischen System die Klassikerverehrung und stellte sich in den Dienst einer solchen Kultur - eigentlich eines Ahnenkultes -, die sich als das genaue Gegenteil des Prozessdenkens bezeichnen ließe. ${ }^{13}$

Seit der europäischen Querelle des Anciens et des Modernes kommt es zum Konflikt, wenn Klassik und Moderne aufeinandertreffen. Goethes Faust selbst lässt sich als Illustration dieses polemischen Epochenkontrasts verstehen, bleibt doch am Ende des Dramas nur noch ein rauchender Scheiterhaufen von der klassischen Überlieferung übrig, die in Gestalt von Philemon und Baucis auf den von Faust und Mephisto repräsentierten Modernisierungsprozess trifft. Kaum anders ergeht es der chinesischen Klassik im 20. Jahrhundert, wie es

13 Das im Blick auf die geschichtsphilosophische Leerstelle in der chinesischen Geistesgeschichte bedeutendste - und faszinierendste! - Buch hat Wolfgang Bauer geschrieben, der es dann allerdings unter Berufung auf gleichwohl vorhandene chinesische Zeugnisse eines utopischen Denkens gerade auf die Ausnahmen von der ideengeschichtlichen Regel abgesehen hat: „Mit rückwärts gewandtem Kopf - so lautet eines der fast nirgends bestrittenen, sondern allenthalben wie ein Axiom angenommenen Urteile über das große Reich im Fernen Osten - ist China, ein Land ohne Kindheit, bis in unsere Tage hinein durch die Jahrtausende geschritten, alle Ideale in der Vergangenheit, kaum irgendeines in der Zukunft suchend. Für die Berechtigung dieser Meinung [. . . ] lassen sich in der Tat auf den ersten Blick mühelos die verschiedensten Argumente anführen, und doch bedarf auch sie [. . . einer deutlichen Modifizierung“ (Bauer 1974, 22). Insbesondere die Repräsentanten des 4. Mai geben Anlass, von solchen „Modifizierungen“ zu sprechen: „Als sich eine ganze Generation chinesischer Intellektueller im ersten Drittel unseres Jahrhunderts zutiefst verstört ob der vehementen Kraft, die der westlichen Kultur aus ihrem Glauben an Entwicklung und Fortschritt zuzuwachsen schien, in der eigenen Kultur auf die Suche nach der verlorenen Zeit begab, entwickelt der ingeniöse Gelehrte Hu Shih (1891-1962) die erregende Theorie, daß nicht nur das jüdische Volk, sondern auch das der Shang von messianischen Ideen beseelt gewesen sei, und ebenso wie dieses, seine auf politischem Gebiet enttäuschten Heilserwartungen ins Religiöse gerettet habe“ (Bauer 1974, 38). Ausgehend vom 4. Mai schreitet dann Li Dazhao - einer der Gründer der KPCh und ursprünglich Bibliothekar an der Peking Universität - über den Versuch einer Vermittlung zwischen marxistischem Geschichtsdenken und chinesischer Tradition zum Paradigmenwechsel des Fortschritts- und Prozessdenkens weiter (vgl. Bauer 1974, 512-522). - Dazu desgleichen Wolfgang Bauer in seiner Philosophiegeschichte Chinas über die „erkennbare Tendenz“ der verschiedenen chinesischen Philosophieschulen zu „zyklischen Vorstellungen“, zur „Aufmerksamkeit für den Kreislauf der Natur“, zur „Wertschätzung der Geduld, des Wartenkönnens“ und der „Mäßigung“ und über den Konflikt zwischen den Ordnungsprinzipien des vergangenheitsorientierten Konfuzianismus und dem „westlichen Fortschrittsdenken“, mitunter, wie im Fall des Philosophen und Politikers Kang Youweis (1858-1927), „tragisch“ ausgetragen in den intellektuellen Biografien der Zeitgenossen des 4. Mai (Bauer 2006, 27 und 311-312). 
dann später der unversöhnliche Kampf der Kulturrevolution gegen die Tradition drastisch vor Augen führt.

Konsequent hatte Guo Moruo zunächst während der 1920er Jahre unter dem Eindruck der 4.-Mai-Bewegung den Handlungsverlauf von Faust I und dann seit den 1940er Jahren im Banne des Bürgerkriegs das tragische Geschehen in Faust II auf die Verhältnisse der chinesischen Revolutionsepoche übertragen, um schließlich - abermals Lukács' Deutungsmodell aufgreifend - in Fausts Schlussvision „Solch ein Gewimmel möcht ich sehn/Auf freiem Grund mit freiem Volke stehn“ (V. 11579-11580) den Vorschein der revolutionären „Volksbefreiung“ in China zu erkennen:

Individualism is the core of capitalism. Capitalism represents a progress compared to feu-
dalism [und die Abbildung dieses Fortschritts, so Guo, sei der konkrete historische Gehalt
von Goethes Text] . . . . But the consciousness of Faust does not stop there; rather, it
moves forward. Though it is a fantasy, Faust nevertheless wants to „open land to live mil-
lions“ and hopes to see „free people living on the free land“. This is a step from indivi-
dualism toward people-centrism (renmin benwei zhuyi) . . . . This is . . . a leap forward
beyond Goethe's own epoch (shidai); though Goethe, together with his Faust, does not
finish this leap, he dreams of it . . . . So the whole tragedy, one can say, is a spontaneous
development toward the awakening of the consciousness of the people (renmin yishi).

(Zitiert nach Wang 2018, 153)

Um aber Goethes vermeintlichen Traum Wirklichkeit werden zu lassen, bedarf es des Fortschritts um jene weitere Etappe im welthistorischen Prozess vom blinden Faust der Tragödie des 19. Jahrhunderts zum chinesischen Faust des 20. Jahrhunderts, der während des Bürgerkriegs in der Rolle des revolutionären Volkes agiert und die Befreiung vollendet. Im Sinne einer solchen Verlängerung der Faustdeutung in die Gegenwart des Jahres 1947 bemerkt Guo Moruo im Vorwort seiner Übersetzung von Faust II:

The Chinese Faust shall never grow old, never be blind, and never die. He will not be satisfied with gaining land from the sea shore, or bestowing democracy in a feudal manner; rather he wants China to become the ocean of democracy, and people to really be the master and take command.

(Zitiert nach Wang 2018, 154)

Über ein derart festgefügtes Geschichtsbild und über die daraus abgeleiteten eindeutigen Direktiven für die politische Praxis verfügte die Bewegung vom 4. Mai 1919 indessen noch keineswegs. Sie ist zunächst vollkommen idealistisch, aber in diesem Idealismus spricht sie den Konflikt zwischen (chinesischer) Klassik und Moderne (im westlichen Verständnis) bereits ganz offen aus. 


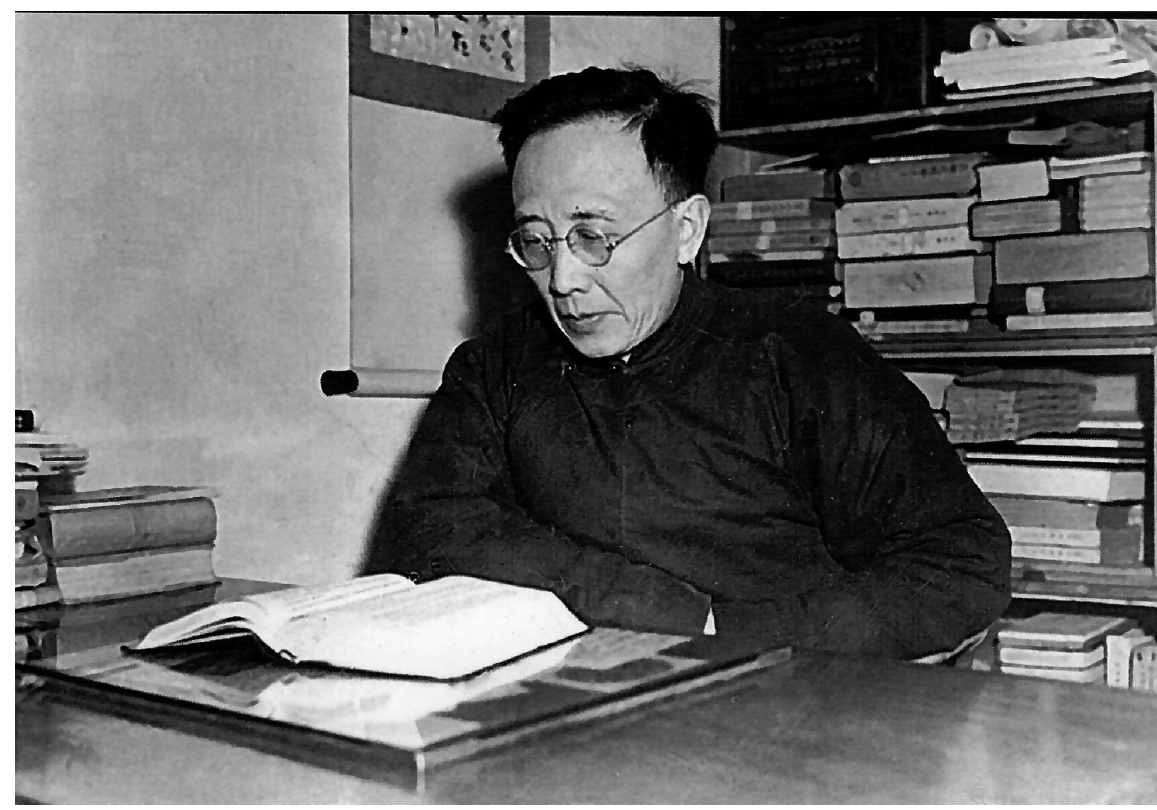

Abb. 5: Guo Moruo um 1945.

\section{Richard Wilhelm}

\subsection{Kiautschou 1899}

Im Zentrum dieser epochalen Auseinandersetzung zwischen Überlieferung und Moderne in China stehen Leben und Werk Richard Wilhelms, des bedeutendsten und wirkmächtigsten deutschen Sinologen des 20. Jahrhunderts. Als sechsundzwanzigjähriger evangelischer Pfarrer und Missionar war Wilhelm 1899 im Auftrag des „Allgemein-evangelisch-protestantischen Missionsvereins“ in der Stadt Tsingtau in eben jenem deutschen Pachtgebiet (Kiautschou/Shandong) angekommen, das dann später zum neuralgischen Bezugspunkt der 4.-Mai-Bewegung und ihrer Proteste gegen den westlichen Kolonialismus werden sollte, da es nicht, wie es den vom amerikanischen Präsidenten verkündeten Prinzipien entsprochen hätte, an China zurückgegeben wurde, sondern 1919 nach den Versailler Bestimmungen Japan zufiel. Im übergeordneten historischen Kontext müsste man Wilhelm auf den ersten Blick denn auch als Repräsentanten oder gar als Agenten des Kolonialismus ansehen, trifft er doch ausgerechnet zur Zeit des sogenannten „Boxeraufstandes“ in China ein, der überdies eines seiner Zentren in der Shandongprovinz hatte. 
$\mathrm{Zu}$ den Ursachen des Aufstandes zählt nicht zuletzt der Protest gegen die christliche Mission, weiterhin der innerchinesische Konflikt zwischen der christlichen Minderheit und der nichtchristlichen Bevölkerungsmehrheit sowie die allgemeine Krisensituation in der Endphase des chinesischen Kaiserreichs, als die Differenzen zwischen reformerischen und konservativen Kräften immer unversöhnlicher hervorbrachen. Dass es für einen liberal gesinnten deutschen Missionar wohl kaum einen noch ungeeigneteren Augenblick für die Aufnahme seiner Tätigkeit in China hätte geben können, das macht ein Blick auf die berühmt-berüchtigte sogenannte „Hunnenrede“ von Kaiser Wilhelm II. deutlich, der dem deutschen Expeditionsheer, das zur Niederschlagung des Boxeraufstandes am 27. Juli 1900 in Bremerhaven aufbrach, die martialischen Worte mit auf den Weg gab:

Ihr wißt es wohl, ihr sollt fechten gegen einen verschlagenen, tapferen, gut bewaffneten, grausamen Feind. Kommt ihr an ihn, so wißt: Pardon wird nicht gegeben, Gefangene werden nicht gemacht. Führt eure Waffen so, daß auf tausend Jahre hinaus kein Chinese mehr es wagt, einen Deutschen scheel anzusehen. Wahrt Manneszucht. Der Segen Gottes sei mit euch, die Gebete eines ganzen Volkes [. . .] Öffnet der Kultur den Weg ein für allemal! ${ }^{14}$

In jenen Kriegsszenen, die Wilhelm im autobiografischen Rückblick auf seine chinesischen Jahre schildert, handelt er den Kaiser-Wilhelm-Direktiven genau zuwider und ermöglicht in seiner Umgebung in Shandong die Vermeidung der kompromisslosen Hunnen-Strategie. ${ }^{15}$ Höchst unorthodox scheint auch Wilhelms Missionsverständnis gewesen zu sein, so dass er im Rückblick auf seine Tätigkeit

14 Überliefert wird die ursprünglich frei gehaltene Rede in mehreren Fassungen, darunter auch eine Version, die den nach China entsandten deutschen Truppen als Vorbild für ihren militärischen Einsatz König Etzel und die Hunnen der Nibelungensage empfahl. In der offiziellen Ausgabe der Kaiserreden, herausgegeben durch den Hofredakteur Johannes Penzler, aus der hier zitiert wird, ist die Hunnen-Passage jedoch gestrichen (vgl. Penzler 1904, 210).

15 Die entsprechenden Kapitel von Richard Wilhelms 1926 erschienenem Rückblick auf seine chinesischen Jahre zeigen ihn gleichsam als Vermittler zwischen den Fronten (vgl. Wilhelm 1980, 44-56). - In zahlreichen Passagen seiner China-Erinnerungen - insbesondere in der Retrospektive auf den Boxer-Konflikt - führt Wilhelm die kolonialistische Ideologie des Kulturkampfes samt ihren Klischees (der „gelben Gefahr“) ad absurdum. So heißt es über die Verhältnisse in der deutschen Kolonie in Tsingtau: „Man war überzeugt von der höheren Kultur Europas, die es zu wahren galt gegen die gelbe Gefahr, ohne zu bemerken, daß man sich im Gegenteil selbst in der Offensive befand und alles tat, um die große Kultur Ostasiens so gründlich wie möglich im Keim zu vergiften“ (Wilhelm 1980, 42). Und über die Zerstörungen und Plünderungen, die dem Einmarsch des europäisch-japanisch-amerikanischen Expeditionskorps (darunter die von Kaiser Wilhelm entsandten deutschen Truppen) im August 1900 
in China selbstbewusst bekennen konnte, keinen einzigen Chinesen getauft zu haben (vgl. Wilhelm 1980, 55). ${ }^{16}$ Er widmete sich in Tsingtau vor allem dem Aufbau von Schulen und Krankenhäusern, dem konzentrierten Studium der chinesischen Schrift und Sprache sowie der Lektüre eben jener chinesischen Überlieferung, die zugleich mit dem Niedergang des Kaiserhauses in eine fundamentale Krise geriet. Für das Studium der klassischen chinesischen Literatur und ihrer kanonischen Texte wie auch für das Verständnis der krisenhaften Umbruchsituation Chinas insgesamt sollte sich nun gerade das deutsche Pachtgebiet Kiautschou, das nach 1914 von Japan besetzt wurde, als ein besonders günstiger Ort erweisen, denn eben dieses gleichsam exterritoriale Gebiet diente sowohl den reform- und revolutionsgesinnten Kritikern des traditionellen chinesischen Herrschaftssystems bis zum Fall des Kaiserhauses als Rückzugsort, wie auf der anderen Seite auch die konservativen Vertreter der alten Gelehrsamkeitstradition dort Schutz suchten, um den kriegsähnlichen Wirren zu entgehen, die durch den Boxeraufstand und die Strafexpeditionen der Kolonialmächte, dann aber auch durch die immer unversöhnlicher aufbrechenden innerchinesischen Konflikte und durch jene den Niedergang des Kaiserhauses begleitenden Diadochenkämpfe verursacht wurden, die ab 1911 die junge Republik sogleich wieder erschütterten, zunächst in der Militärherrschaft Yuan Shikais endeten, um dann während der 1920er Jahre in das Regime der sogenannten Warlords zu münden.

in Peking folgten, schreibt Wilhelm, ironischerweise die Hunnen vor ihren vermeintlich modernen Wiedergängern in Schutz nehmend: „Japanische Truppen waren es, die zuerst in Peking einrückten, und ihnen folgten andere auf dem Fuß. [. . .] so gaben sich die nun siegreich einrückenden Massen redliche Mühe, zu zeigen, daß Roheit und Grausamkeit auf seiten der ,Kulturnationen“ nicht hinter dem zurückblieb, was man an China mit Abscheu verdammte. Die Deutschen haben im Weltkrieg den Titel Hunnen von ihren damaligen Verbündeten erhalten, weil in der Aufregung des Augenblicks den ausziehenden Chinakämpfern die Hunnen als Vorbild mitgegeben worden waren. Diese Beschimpfung war unverdient. Alle Beteiligten zeigten damals aufs unzweideutigste, daß sie solcher Vorbilder nicht bedurften. Was damals an Menschenleben, schuldigen und unschuldigen, vernichtet wurde, was an unersetzlichen Kunstschätzen im Unverstand zugrunde ging, läßt sich nur annäherungsweise abschätzen“ (Wilhelm 1980, 49-50).

16 Wilhelms Selbstverständnis, sein permanenter Widerspruch gegen das offizielle deutsche China-Klischee sowie die historische Situation insgesamt wird man im Auge behalten müssen auch bei einer Kritik seines „Orientalismus“ aus postkolonialistischer Perspektive, an der es naturgemäß nicht gefehlt hat, etwa in Adrian Hsias Analyse von Wilhelms „Sinophilie“ in ihrer Verbindung zur Ideenwelt Goethes (Hsia 2010, hier 123-136, das Kapitel „Richard Wilhelm und Goethes Affinitäten zur chinesischen Geisteswelt“). 
Inmitten der tumultuarischen historischen Lage vermag sich Wilhelm nun ausgerechnet im deutschen Pachtgebiet (und nach 1914 im japanischen Besatzungsgebiet) dem Studium der klassischen chinesischen Literatur zu widmen. Umgeben und beraten von den Gelehrten der chinesischen Philosophie und Literatur, die ihrerseits an diesem Ort Zuflucht gesucht haben, entstehen hier Richard Wilhelms berühmte Übersetzungen der chinesischen Klassiker. ${ }^{17}$ In Deutschland erreichen Wilhelms Übersetzungen der Klassiker der chinesischen Literatur und Philosophie nach dem Ersten Weltkrieg ein großes Publikum und konnten solchermaßen zum Fundament einer neuen, die kolonialistischen und ideologischen Stereotype überwindenden China-Wahrnehmung werden. Bis zum heutigen Tag sind auf dem deutschen Buchmarkt Wilhelms Übersetzungen und Kommentare der chinesischen Klassik präsent, wie auch in Europa und Amerika Wilhelms Ausgaben, nun ihrerseits in die jeweiligen Landessprachen übersetzt, nach wie vor weit verbreitet sind.

17 Den „deutsch-chinesischen Kulturaustausch“ und die konzentrierten Klassikerstudien vor dem Hintergrund des epochalen Umbruchs schildert Wilhelm anschaulich im 11. Kapitel („Die Alten von Tsingtau“) seiner Autobiografie: „Die chinesische Revolution erhob ihr Haupt. Tsingtau blieb ruhig, während überall im chinesischen Reich die Stürme tobten“ (Wilhelm 1980, 210). - Dankbar erwähnt Wilhelm in seinen seit 1910 im Jenaer Diederichsverlag in rascher Folge erschienenen kommentierten Übersetzungen die Hilfe der chinesischen Gelehrten, die nun ausgerechnet bei ihm in Tsingtau Schutz gesucht hatten, so etwa 1912 im Vorwort zu Das wahre Buch vom südlichen Blütenland: „Immerhin sind mir die Zeitumstände zu Hilfe gekommen. Unter den chinesischen Beamten, die sich infolge der Unruhen in das sichere Tsingtau zurückgezogen haben, befindet sich auch einer, der wohl zu den besten Kennern Dschuang Dsis unter den gegenwärtigen chinesischen Gelehrten gehört. Ich war in der Lage, ihn bei schwierigen Fragen, wo die gewöhnlichen Literaten gänzlich zu versagen pflegen, zu Rate zu ziehen, und verdanke ihm manche wertvolle Aufklärung. [. . .] Tsingtau, 21. März 1912 Richard Wilhelm“ (Dschuang Dsi 2008 [1912], 19). - Über den Beobachterposten, den Wilhelm in Tsingtau im „Windschatten“ der turbulenten Zeit einnehmen konnte, bemerkt Wolfgang Bauer im Vorwort zu Wilhelms Autobiographie: „So zogen vor Richard Wilhelms Augen wie im Zeitraffer Chinas verflossene Jahrhunderte vorüber, und es gelang ihm durch diese einmalige Gunst der Umstände, gepaart mit seinem wachen Interesse, die Kultur Chinas in ihren tieferen historischen Dimensionen zu erfassen, wie es zu einer anderen Zeit und an einem anderen Ort wohl kaum möglich gewesen wäre. Die merkwürdig verwunschene Atmosphäre, in der sich das alles abspielte, ist in verschiedenen Abschnitten des Buches eingefangen, am eindrucksvollsten wohl in dem Kapitel über ,Die Alten von Tsingtau““ (Wilhelm 1980, 15). 


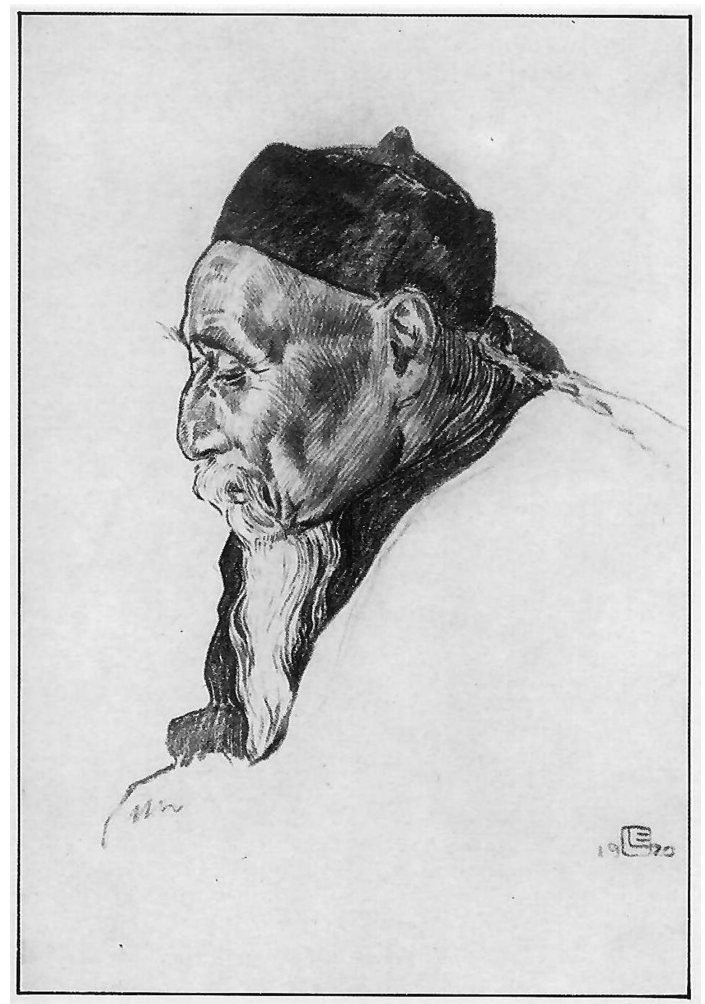

Abb. 6: Die Federzeichnung aus Richard Wilhelms Buch Die Seele Chinas zeigt den chinesischen Gelehrten Lao Nai Hsüan, unter dessen Anleitung Wilhelm in Tsingtau das Buch der Wandlungen studierte.

\subsection{Modernebegeisterung und Modernekritik: Chinesisch- deutsche Paradoxie}

Will man die Ursachen für den wahrhaft atemberaubenden Erfolg der Bücher Wilhelms verstehen, die in zahllosen Auflagen und Hunderttausenden von Exemplaren verkauft wurden, so wird man einmal mehr die epochale Krise der alten Welt und ihrer Überlieferung, nun allerdings in Europa und in Deutschland, ins Auge fassen müssen. Denn in demselben historischen Augenblick, da im Osten das alte chinesische Reich zerbrach, stand im Westen dem deutschen Kaiserreich seine finale Niederlage bevor, die mit dem Ende des Ersten Weltkriegs und den Versailler Verträgen besiegelt wurde. In Deutschland allerdings ging mit der Erschütterung der alten Reichsidee und ihrer ständischen und bür- 
gerlichen Traditionen zugleich die Krise der Fortschritts-, Modernisierungsund Technikbegeisterung einher, die im Verlaufe des Ersten Weltkriegs, in seinen endlosen Materialschlachten insbesondere, ihre schreckliche Ernüchterung erlebte. Die Kritik der Technik, die Kritik der Moderne und mithin die Kritik des ehedem säbelrasselnden Nationalismus steht in Deutschland nach der Kriegskatastrophe auf der Tagesordnung. ${ }^{18}$

Nach der traumatischen Kriegserfahrung nimmt ein großes Publikum in Deutschland Richard Wilhelms Übersetzungen der chinesischen Klassiker gleichsam als Wiederentdeckung einer Kultur der Meditation, Nachdenklichkeit und Spiritualität auf, die in Europa offenbar verloren gegangen ist und nun in Anlehnung an die „Weisheit des Ostens“ wieder regeneriert werden soll, um dem allgemeinen geistigen Orientierungsverlust $\mathrm{zu}$ entrinnen. Ohne Übertreibung wird man konstatieren können, dass die komplette Umwertung des deutschen Chinabildes von der aggressiven Beschwörung der „gelben Gefahr“ zur erwartungsvollen Bewunderung Chinas und seiner großen kontemplativen Tradition auf die gewaltige Übersetzungsleistung Richard Wilhelms zurückgeht.

So zeigt sich uns in der globalen historischen Perspektive ein bemerkenswertes ideengeschichtliches Paradoxon: Gewinnt man in China nach dem Ende des kaiserlichen Herrschaftssystems und in der damit einhergehenden Krise der konfuzianischen Ideale neue Inspiration aus dem Fortschrittsversprechen der westlichen, technikbegeisterten, rationalistischen Moderne, so antwortet man im Westen auf die fundamentale Enttäuschung desselben Fortschrittsversprechens durch die Katastrophe des Weltkriegs in einer exakt gegenläufigen Operation und sucht neue Orientierung nun ausgerechnet in der modernitätsfernen Geisteswelt der chinesischen Philosophie. Mitten in dieser interkulturellen Paradoxie steht Richard Wilhelm; aus dieser Position erst gewinnen seine Person und sein Werk ihre beeindruckende historische Wirkungsmacht. Wilhelm agiert auf der Grenzlinie zwischen Westen und Osten, Modernisierungsbegeisterung und Traditionsgläubigkeit, Kolonialismus und antikolonialistischer Selbstverteidigung.

18 Der Jenaer Eugen-Diederichs-Verlag, in dem Wilhelms Übersetzungen erschienen, versammelte seit 1908 das weite Spektrum der Modernismuskritik im Zeichen der Mystik. Innerhalb des zunächst denkbar heterogenen Diederich-Spektrums gewann im Laufe der 1920er Jahre die reaktionäre Fraktion an Einfluss. Wilhelm stand zu ihr, sowohl in politischer wie auch in intellektueller Hinsicht, in großer Distanz, nachdem er sich in China den „Modernisierern“ an der Peking Universität um Cai Yuanpei angeschlossen hatte. 


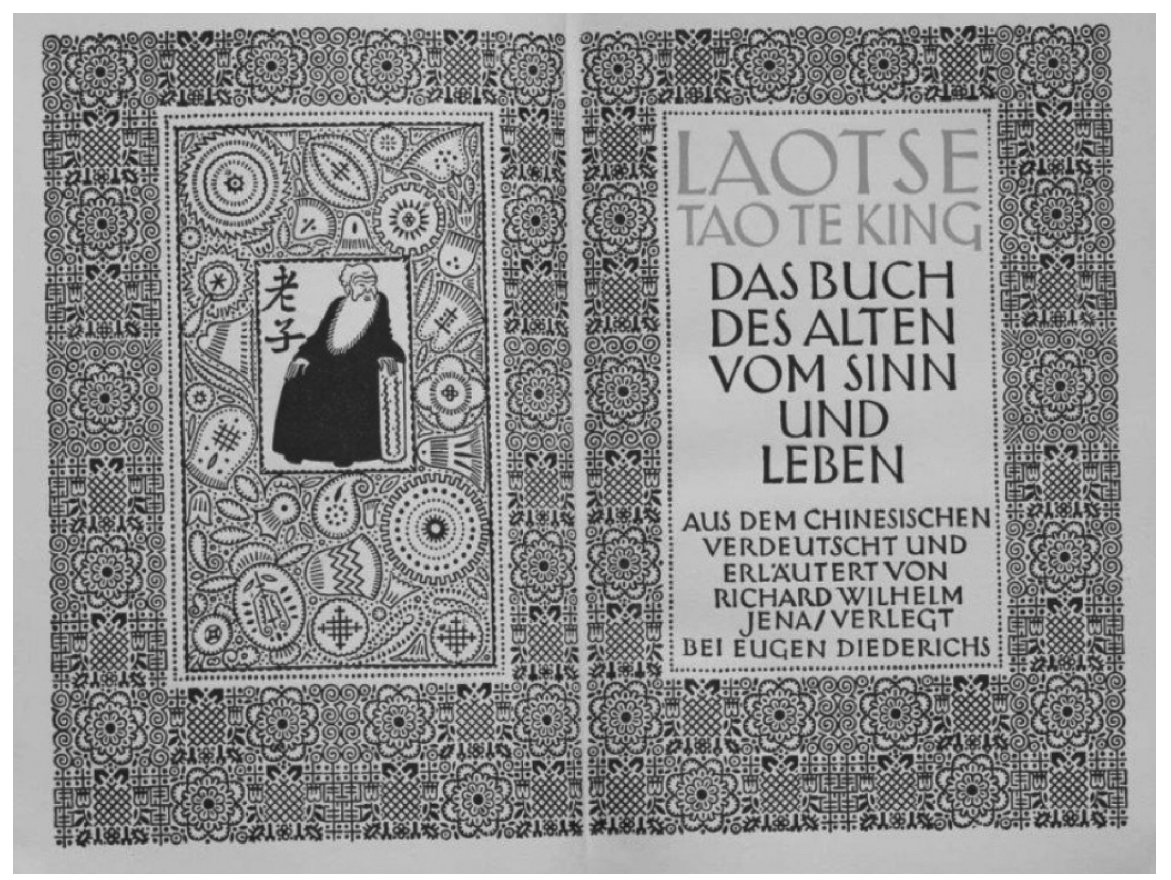

Abb. 7: Umschlag von Richard Wilhelms Übersetzung des Tao Te King (erstmals 1911) in einer Ausgabe des Eugen Diederichs Verlages in Jena von 1921.

\subsection{Goethe als Übersetzungshelfer}

Um nun in diesem ungeheuren Spannungsfeld zwischen den Widersprüchen vermitteln zu können, beruft sich Wilhelm auf Goethe, und dies in mehrfacher Hinsicht. Schaut man in die Kommentare und Erläuterungen, die Wilhelm seinen Übertragungen aus dem Chinesischen stets hinzufügte, wird man auf zahlreiche Goethe-Verweise und Goethe-Zitate stoßen, die sämtlich Wilhelms Überzeugung geschuldet sind, es gebe über alle Sprach- und Kulturdifferenzen hinweg eine prinzipielle Analogie zwischen Goethes Denken, seiner Naturanschauung vor allem, und der klassischen chinesischen Philosophie des Daoismus und Konfuzianismus. Komparatistische Belege für eine solche kulturelle Analogie führt Wilhelm dann 1927 in dem für diese Thematik grundlegenden Aufsatz Goethe und die chinesische Kultur an. Über Goethes „,innere Verwandtschaft mit dem chinesischen Wesen" - worunter man in Wilhelms Argumentation das spezifisch kontemplative und meditative Element der klassischen chinesischen Philosophie und Kunst zu verstehen hat - heißt es hier im Blick 
auf Goethes Gedichtzyklus Chinesisch-deutsche Jahres- und Tageszeiten, darin insbesondere das achte Gedicht („Dämmrung senkte sich von oben“; Goethe 1998 [1827], 18) ausgezeichnet sei durch „chinesische reinste Stimmung“:

Was aber die deutsche [d. i. Goethes] und die chinesische Poesie am meisten verbindet, das ist die vollkommene Auflösung des Zuständlichen in dynamische Stimmung. Nichts Beschreibung, alles Vorgang, Bewegung, Übergang. Diese feinste Bewegung des Geistigen findet sich ja selbst in den chinesischen Bildern der Sungzeit in ihrem fein ausgeglichenen Wechsel von Zeichnungen und leerem Raum. Hier haben wir den unsichtbaren, nichts machenden und doch ewig wirkenden Sinn der Welt bei seinem Wirken belauscht.

(Wilhelm 1927, 309 und 313) $)^{19}$

Das zehnte („Als Allerschönste bist du anerkannt“) und elfte Gedicht („Mich ängstigt das Verfängliche“) desselben Zyklus nimmt Wilhelm dann zum Anlass, Goethes ,intuitive“ Nähe zur daoistischen Mystik und ihren Meditationen über den „ewig wirkenden“, gleichwohl verborgenen Weltsinn, zu erläutern:

Im zehnten Stück, das von der Blumenkönigin spricht, als die in China nicht die Rose, sondern die Päonie verehrt wird, ist der Gegensatz zwischen der Tatsache der Anschauung und dem tieferen Sinn, dem Gesetz, ausgesprochen, ein Gedanke, der im 2. Gedicht [dem elften des goetheschen Zyklus], wo das Beängstigende der Vergänglichkeit alles Erscheinenden erwähnt wird, noch mehr herausgehoben wird. Inmitten der vergänglichen Erscheinungen, wo nichts verharret, alles flieht, wirkt das Unvergängliche, das ewige Gesetz. Diese Anschauung ist ebenfalls ein intuitives Zusammentreffen mit der Weisheit des Buches vom Sinn und Leben [d.i. Laotses Tao Te King], wo ebenfalls der ewige Sinn erwähnt wird, der zwar nicht unmittelbar der Anschauung zugänglich ist, aber eben des-

19 Wilhelms Aufsatz erscheint anlässlich des hundertsten Jahrestages der Publikation von Goethes Gedichtzyklus Chinesisch-deutsche Jahres- und Tageszeiten (Goethe 2006a [1827]). Die polyglotte philologische Weite von Wilhelms Blick auf Goethe sowie Wilhelms universeller intellektueller Horizont gewinnen ihr unzeitgemäßes Profil im Kontrast zu den penetrant deutschtümelnden Studien von Hermann August Korff und Herbert Cysarz, die am Beginn desselben Jahrbuchs stehen. Gilt ihr Interesse dem „Ideal einer wahren Lyrik und speziell einer deutschen Lyrik“ (wie Wilhelm 1927, 3) oder Schiller als dem „volkhafteste[n] deutsche[n] Seher, Lehrer, Führer“ (wie Wilhelm 1927, 121), so lässt Wilhelm, gleichsam programmatisch für seine deutsch-chinesische Philologie, den Aufsatz Goethe und die chinesische Kultur ausklingen in einem Zitat aus Goethes Gespräch mit Eckermann über die „Weltliteratur“: „wenn wir Deutsche nicht aus dem engen Kreise unserer eigenen Umgebung herausblicken, so kommen wir gar zu leicht in pedantischen Dünkel. Ich sehe mich daher gern bei fremden Nationen um und rate jedem, es auch seinerseits zu tun“ (Wilhelm 1927, 316). - Auf sinologischem Terrain provozierte Wilhelms Rekonstruktion von Goethes „intuitiver“ Nähe zur Ideenwelt des alten China skeptische und kritisch-relativierende Bemerkungen, zugleich jedoch eine vorsichtige Bestätigung der komparatistischen Befunde, so etwa bei Wolfgang Bauer (1972), Adrian Hsia (2010, 129-136) und Günter Debon (2000) und insbesondere dann bei Helwig SchmidtGlintzer (2006, 83 und 95). 
halb ewig ist, wie das gleich im ersten Kapitel des Buches vom Sinn und Leben ausgesprochen ist.

$\left(\right.$ Wilhelm 1927, 314) ${ }^{20}$

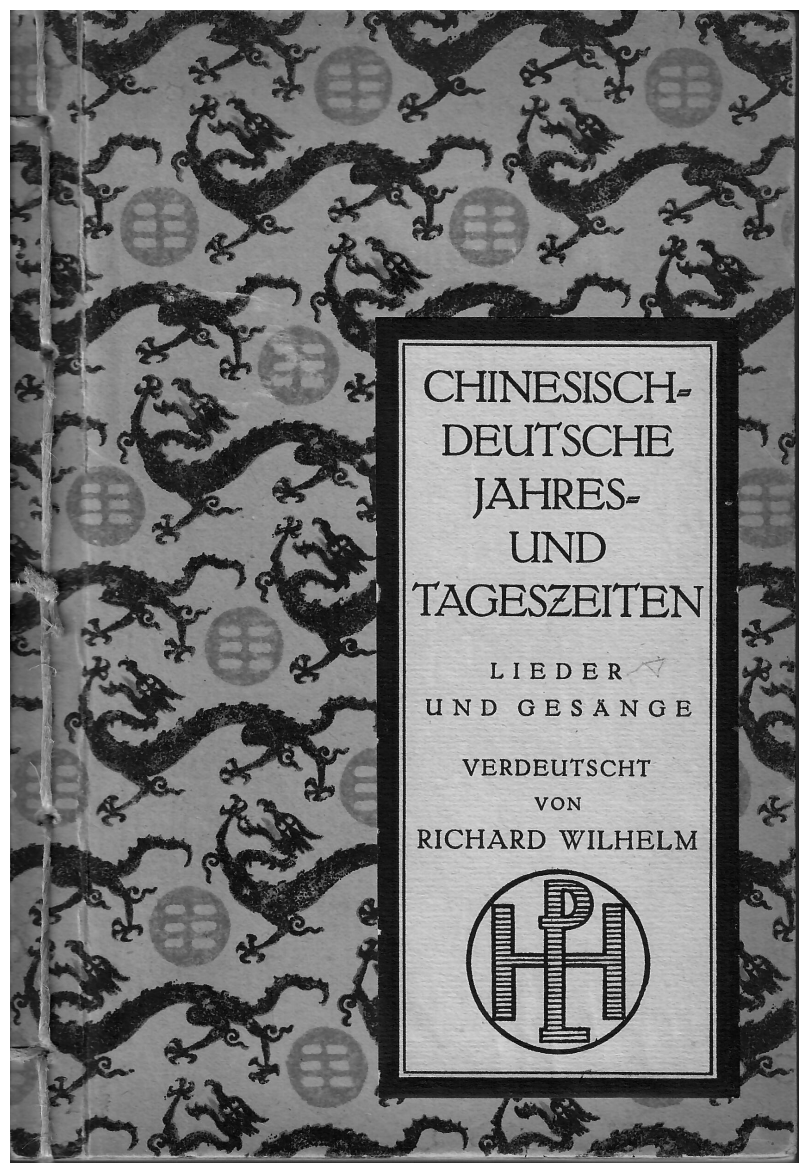

Abb. 8: 1922 erschien die von Richard Wilhelm übersetzte und herausgegebene Anthologie klassischer chinesischer Lyrik mit dem Titel des goetheschen Gedichtzyklus ChinesischDeutsche Jahres- und Tageszeiten.

20 Es liegt dann in der Konsequenz der von Wilhelm entworfenen Goethe-China-Analogie im Zeichen der Mystik, dass er in seiner 1911 in Tsingtau abgeschlossenen Laotse-Übersetzung den „nichts machenden und doch ewig wirkenden Sinn der Welt“, wie ihn auch der sechste Abschnitt des Tao Te King evoziert, im Rückgriff auf den Goethes Faustdrama abschließenden „Chorus Mysticus“ das „Ewig-Weibliche“ nennt (Laotse 2019 [1911], 16). - Passend dazu Wilhelm im Kommentar zum zweiten Abschnitt des Tao Te King über die „Lehre des Wirkens ohne Handeln“, die in der universellen Mystik „durch alle Zeiten“ hindurch und mithin auch bis zu Spinoza und Goethe gehe (Laotse 2019 [1911], 106). 


\subsection{Chinesisch-goethesche Willenskritik}

Goethes Dichtung übernimmt in Wilhelms Auslegung zunächst in einem ganz praktischen und konkreten Verständnis eine Vermittlerrolle, insofern Wilhelm in den Fußnoten und Erläuterungen seiner Übersetzungen auf Goethes Werk verweist und daraus zitiert, um auf diese Weise dem deutschen Publikum die unbekannte Denkweise der chinesischen Texte nahezubringen, so etwa in den Erläuterungen zu dem das Buch der Wandlungen/I Ging eröffnenden Zeichenund Begriffspaar des „Schöpferischen“ und des „Empfangenden“, darin Wilhelm der chinesischen Geisteswelt Goethes Naturbegriff und das mit ihm verbundene Prinzip der Metamorphose zur Seite stellt, wie sie zum Ausdruck kommen in jenem ursprünglich in den Schriften Zur Morphologie in dem Kapitel „Bedenken du Ergeben“ veröffentlichten Gedicht Goethes, das mit den Versen beginnt: „So schauet mit bescheidenem Blick/Der ewigen Weberin [d. i. die schöpferische Natur, die Natura naturans] Meisterstück“ (Goethe 2006b). ${ }^{21}$ Das Gedicht des Naturforschers Goethe führt Wilhelm in diesem Fall in der Fußnote seiner I-Ging-Übersetzung an, um die für das Buch der Wandlungen charakteristische Kritik des individuellen Willens und der subjektiven Willkür sowie die damit einhergehende Verbindung von Naturanschauung und Ethik zu illustrieren, die in dem chinesischen Lehrsatz zusammengefasst wird: „Hat der Edle etwas zu unternehmen und will voraus, so geht/er irre; doch folgt er nach, so findet er Leitung“ (I Ging 1986 [1924], 35). Wir können ergänzen: Die Unternehmung des Edlen, von der die klassische chinesische Ethik (vor allem Konfuzius) stets spricht, hat sich an den Möglichkeiten der realen Lage zu orientieren. Dort findet der Edle Leitung, die er dann „beharrlich“ umsetzt und nicht etwa in einem Willensakt erzwingt.

Die analoge Kritik des unbedingten Willens und seines Vorwärtsdrangs wird in den von Wilhelm zitierten, desgleichen Naturanschauung und Ethik zusammenfassenden Goethe-Versen „So schauet mit bescheidenem Blick/Der ewigen Weberin Meisterstück“ ausgesprochen. Seid im erkenntniskritischen Sinne bescheiden, so Goethes philosophischer Appell, scheidet subjektive Verzerrungen aus eurer Weltwahrnehmung aus, die Erkenntnis stehe nicht unter der Herrschaft eures Willens, sondern folge der „ewigen Weberin Meisterstück“ und nehme Rücksicht auf die Realitäten der Natur und der Gesellschaft. Und

21 An anderer Stelle, im 3. Band der 1827 von Goethe selbst edierten Ausgabe letzter Hand, schließen die von Wilhelm zitierten Zeilen den Gedichtzyklus (im Kapitel „Gott und Welt“) ab, der auch Goethes Metamorphose-Dichtungen enthält (Goethe 2006d, 150-155, hier 155). Dieselben stehen in Wilhelms Goethe-China-Analogie erst recht in geistesverwandter Nähe zum I Ging und zu seinem Grundprinzip der „Wandlung“. 
schließlich lautet im I-Ging-Kommentar Wilhelms Paraphrasierung der chinesisch-goetheschen Lehre, die man durchaus als ein Vermittlungsprogramm verstehen kann, das er am Beginn des Jahrhunderts der Extreme seinen vom politischen und ideologischen Gefecht aufgeregten Zeitgenossen in China und Deutschland empfiehlt:

Auf menschliche [politische, ökonomische, gesellschaftliche] Verhältnisse übertragen, handelt es sich darum, der Lage entsprechend sich zu verhalten. Man ist nicht in selbständiger Stellung, sondern als Gehilfe tätig. Da [in der Arbeit als Gehilfe] gilt es etwas zu leisten [als Politiker, Unternehmer, nicht anders als edler Herrscher, Weiser und Erkennender, sie alle sind als Gehilfen tätig, im Dienst eines größeren Ganzen]. [. . .] Der Edle läßt sich leiten. Er geht nicht blindlings voran, sondern er entnimmt den Verhältnissen, was von ihm verlangt wird [. . . ].

(I Ging 1986 [1924], 35-36)

Der „Edle“ als orientierungsstiftende Idealgestalt steht vor allem in den Gesprächen des Konfuzius im Zentrum der philosophisch-ethischen Unterweisungen. Auch von hier aus zieht Wilhelm über die Zeit- und Kulturgrenzen hinweg die Verbindungslinie zu Goethes Werk und $\mathrm{zu}$ seinem subjektivitätskritischen Bildungsideal, das Wilhelm naturgemäß in den Chinesisch-deutschen Jahres- und Tageszeiten wiederfindet:

Und auch das letzte der Gedichte mit seiner Quintessenz: „Sehnsucht in’s Ferne, Künftige zu beschwichtigen,/Beschäftige dich hier und heut im Tüchtigen“ ist durchaus in Übereinstimmung mit der chinesischen Lebensweisheit. Man vergleiche nur das Wort des Meisters Kung, das er im Abschluss an das 52. Zeichen „das Stillehalten“ des Buchs der Wandlungen ausgesprochen hat: „Der Edle geht mit seinen Gedanken nicht über seine Lage hinaus.“

(Wilhelm 1927, 314; Goethe 2006a [1827], 20) ${ }^{22}$

\subsection{Faust und Prometheus: Goethes unklassische Protagonisten des Sturm und Drang}

Wenn wir an dieser Stelle für einen Augenblick im Horizont der Goethe-ChinaAnalogie innehalten, so fällt uns auf, dass sich Wilhelm in den Kommentaren seiner I-Ging-, Laotse-, Dschuang-Dsi- und Konfuzius-Übersetzungen auf den klassischen und nachklassischen Goethe bezieht. In Goethes Dichtungen gegenwärtig sind freilich auch die modernen voluntaristischen Gegenpositionen

22 Dazu der 28. Lehrsatz (über die „Bescheidenheit“) aus dem 14. Buch der Gespräche in Wilhelms Konfuzius-Übersetzung: „Meister Dsong sprach:,Der Edle geht in seinem Denken nicht über seine Stellung hinaus““ (Konfuzius 2019 [1910], 229). Zur Idealfigur des „Edlen“ bei Konfuzius vgl. Gu 1999, 133-144. 
zur naturphilosophischen Kontemplation. Gerade diese Willensdirektiven jedoch legt Goethe seinen prominentesten poetischen Figuren, also Werther, Faust und Prometheus, in den Mund. In den ursprünglichen, frühesten Fassungen der Werther-, Faust- und Prometheustexte, die zu Zeiten von Goethes Sturm-undDrang-Epoche und ihrer Genieästhetik entstanden waren, geschah das sicherlich in einem identifikatorischen Sinne. Wenn wir also in Wilhelms Goethe-Fußnoten und Erläuterungen zum Buch der Wandlungen und zu den Gesprächen des Konfuzius lesen, dass der Edle dann in die Irre geht, wenn er vorwärts will, dass er indessen in ruhiger Betrachtung der gegebenen Bedingungen, die Leitung findet, der er folgen soll, dass er sich in seinem Urteil zurückhaltender Bescheidenheit befleißigen und seine Erkenntnisse nach dem Vorbild der Kontemplation der Natur des Meisterstücks der ewigen Weberin - gewinnen möge, dann hören wir im Kontrast $\mathrm{zu}$ diesen chinesisch-deutschen Kontemplationsmaximen zugleich die ganz anderslautenden modernen Willensdirektiven mit, die Prometheus und Faust der sie umgebenden Wirklichkeit und Ideenwelt entgegenschleudern.

Prometheus' gegen Zeus und mithin gegen die Überlieferung insgesamt aufbegehrende Verse lauten in Goethes Sturm-und-Drang-Hymne: „Hier sitz’ ich forme Menschen/Nach meinem Bilde/Ein Geschlecht das mir gleich sei/Zu leiden weinen,/Genießen und $\mathrm{zu}$ freuen sich,/Und dein nicht $\mathrm{zu}$ achten/Wie ich“ (Goethe 2006 [1773/1774], 229). Die ganze Welt soll Ich werden. Statt sich in Zeus' Schöpfung oder im Kosmos der Natur einzurichten und sich der bestehenden Ordnung (der „Lage“!) anzupassen, kündigen Prometheus und das ihm nachfolgende prometheische Geschlecht alle Pietät auf -,Ich dich ehren? wofür?“ (Goethe 2006 [1773/1774], 230) - und begehren, eine neue Welt mit ihren eigenen Händen und durch eigene Arbeit zu erschaffen. Den prometheischen Voluntarismus - dem bescheidenen Blick des Edlen im I Ging und beim klassischen Goethe radikal zuwiderlaufend - vernehmen wir auch aus Fausts Mund: „Allein ich will!“ (Goethe 2017, V. 1784). Die Variationen dieses modernen Willensevangeliums Fausts lauten, um nur die beiden prominentesten anzuführen: „Und Fluch vor allen der Geduld!“ (Goethe 2017, V. 1606) und daran anschließend: „Nur rastlos betätigt sich der Mann“ (Goethe 2017, V. 1759).

Die gleiche Ungeduld Fausts formt den spirituellen Beginn des Johannesprologs „im Anfang war das Wort!“ (Goethe 2017, V. 1224/Joh. 1,1) um in die praktische Fassung „im Anfang war die Tat!“ (Goethe 2017, V. 1237). Ist doch das „Wort“ im religiösen Horizont der Bibel der „Logos“ der Schöpfung - weshalb neuere chinesische Faustübersetzungen den Johannesprolog- respektive FaustVers (Goethe 2017, V. 1224) in der Wendung „Im Anfang war Dao“ wiedergeben. Gerade weil jedoch Logos - und Dao - als geistige Prinzipien den menschlichen Willen transzendieren, sieht sich Faust zur eigenen Weltschöpfungstat herausgefordert. $\mathrm{Zu}$ ihr treibt ihn ein ganz anderer „Geist“, der überlieferte oder 
naturgegebene Bedingungen partout nicht ertragen kann, „immer vorwärts“ (Goethe 2017, V. 1857).

Der Edle des I Ging, wie wir uns erinnern, „will“ indessen gerade nicht „,voraus“ und „immer vorwärts“ drängen, weil er sonst „irre“ geht. Faust jedoch folgt der Leitung seines eigenen Willens bis zur Weltneuschöpfung im fünften Akt des zweiten Tragödienteils, wo er dann proklamiert: „Das verfluchte hier!/ Das eben, leidig lastet’s mir“ (Goethe 2017, V. 11233-11234). Das Hierseiende die „Lage“ in den Worten von Wilhelms I-Ging- und Konfuzius-Kommentierung nimmt sich in Fausts Augen als Beleidigung aus, weil es Voraussetzungen und Bedingungen enthält, die seinen Willen einschränken. Daher er denn erst einmal - mit Mephistos Hilfe - die geschichts- und naturbedingten Prägungen der Wirklichkeit negiert und das Hiersein in eine Tabula rasa verwandelt, auf der sich sein Willen bedingungslos entfalten kann. Im konkreten Fall des fünften Aktes sind es Garten, Hütte, Kapelle und Lindenhain von Philemon und Baucis, die Fausts Willen zur Weltneuschöpfung entgegenstehen und daher verschwinden müssen: „Die wenig Bäume, nicht mein eigen,/Verderben mir den Weltbesitz./Dort wollt' ich, weit umherzuschauen,/Von Ast zu Ast Gerüste bauen,/Dem Blick eröffnen weite Bahn,/Zu sehn, was alles ich getan,/Zu überschaun mit einem Blick/Des Menschengeistes Meisterstück“ (Goethe 2017, V. 11241-11248). Fausts stolzer Blick auf sein eigenes „Meisterstück“ ist das exakte Gegenbild zu der von Richard Wilhelm in seiner I-Ging-Erläuterung zitierten naturphilosophischen Maxime Goethes „So schauet mit bescheidenem Blick/Der ewigen Weberin Meisterstück.“

Betrachten wir Wilhelms Entwurf einer Goethe-China-Analogie und die Auswahl seiner Zitate aus Goethes klassischen und nachklassisch-späten Dichtungen in den Erläuterungen zu den I-Ging-, Laotse- und Konfuzius-Übersetzungen, so bemerken wir also auf der anderen Seite zugleich die gewaltige Differenz, in der die für den jungen und vorklassischen Goethe charakteristische Genie- und Willensästhetik zu den Ordnungsgedanken der klassischen chinesischen Philosophie steht. Einerlei ob man auf die hochemotionalen Herzensergüsse und Willensparolen Werthers, Prometheus' oder Fausts schaut, so gerät in der vergleichenden Perspektive stets der äußerste Gegensatz zu der in den großen Schulen der chinesischen Philosophie erklingenden willenskritischen Lehre in den Blick. Noch polemischer gestaltet sich die Konstellation, wenn wir der Karriere von Goethes Sturm-und-Drang-Protagonisten folgen bis zu Marx’ Aktualisierung der archetypischen Rebellion gegen den Götterhimmel und bis zur Nobilitierung von Prometheus zum einzigen „Heiligen“ der Moderne. Dass der rebellische Held einer mit der Überlieferung kompromisslos brechenden revolutionären Praxis zugleich, wie Marx es will, als Repräsentant der wahren Philosophie agiert, das ist unter dem Horizont von Konfuzius und 
Laotse schlechterdings unvorstellbar, wie dann auch die elfte Feuerbachthese und der aus ihr hervorgehende moderne Praxis- und Weltveränderungskult mehr noch als dem europäischen Idealismus den Meditations- und Kontemplationsexerzitien des Ostens den Garaus machen.

\section{6 „Titanisches Streben“: Wilhelms Faust-Vorlesung an der Peking Universität}

Von jenem goetheimmanenten Widerspruch - zwischen faustisch-prometheischem, „revolutionärem“ Voluntarismus und klassisch-naturphilosophischer Kontemplation bzw. „konservativer“ Willkürkritik - und von den entsprechend gegensätzlichen Möglichkeiten, Goethe auf die chinesische Ideenwelt zu beziehen, lässt sich der Gedankengang fortsetzen bis zur paradoxen Koinzidenz der sowohl von Guo Moruo wie auch von Richard Wilhelm zur gleichen Zeit am gleichen Ort entworfenen Goethe-China-Analogien. Dazu zählt auch jenes Goethe-Verständnis Richard Wilhelms, das er in China Anfang der 1920er Jahre in einer Faust-Vorlesung an der Peking Universität ausformuliert hat. Nach seinem ersten, von 1899 bis 1920 über zwanzig Jahre andauernden China-Aufenthalt war Wilhelm von 1922 bis 1924 als Berater des deutschen Botschafters nach Peking zurückgekehrt. Während dieser Zeit nahm er an der Peking Universität eine Lehrtätigkeit auf, zu der auch die Faust-Vorlesung gehörte. ${ }^{23}$

Tritt Goethe in den Kommentaren zu Wilhelms Übersetzungen aus dem Chinesischen als Vermittler zwischen der chinesischen und der deutschen bzw. westlichen Ideenwelt auf, so nimmt Goethe in Wilhelms Faustdeutung die Gestalt eines Vermittlers zwischen Tradition und Moderne an, eine Textauslegung, die wir als Wilhelms dezente Reaktion auf die revolutionäre Umbruchsituation in China während der 1920er Jahre und auf die modernisierungsbegeisterte chinesische Faustrezeption beziehen können. Zur gleichen Zeit also, da Guo Moruo Goethes Faust als Apologie des Emanzipationsversprechens der Moderne liest und später das auf Hegel zurückgehende perfektibilistische Tragödienverständnis im Sinne von Marx' Prometheus- und Faustbegeisterung als gleichsam vorbildliches Modernisierungsmodell in die chinesische Debatte des 20. Jahrhunderts einführt,

23 An der Peking Universität konnte ich im Sommersemester 2018 mit der freundlichen Hilfe von Herrn Hu Zhenghua in der dortigen Universitätsbibliothek das maschinenschriftliche Manuskript von Wilhelms Faust-Kommentar einsehen, auf dessen Grundlage er Anfang der 1920er Jahre an der Peking Universität unterrichtet hat. Der Titel auf dem Manuskripteinband lautet: „Kommentar zu Goethes Faust von Dr. Richard Wilhelm“ (im Folgenden zitiert unter „Wilhelm: Faust-Kommentar“ bzw. „WFK“). 
hält Wilhelm an der Peking Universität eine Faust-Vorlesung, in der er seine chinesischen Hörer auf die immanente Faustkritik des Faustautors Goethe hinweist auf Goethes Kritik also der prometheischen Rebellion -, und zwar im Blick auf den metaphysisch-philosophischen Rahmen des Fausttextes (vgl. WFK, 47), der Guo kaum interessiert oder allenfalls, was den himmlischen Tragödienschluss angeht, als Fortschritts- und Freiheitsallegorie, wie das auch für Georg Lukács’ Fauststudien typisch ist.

„Titanisches Streben“ lautet das Schlüsselwort in Wilhelms Faust-Kommentar. Im Unterschied jedoch zum hegelianischen und, daran später anschließend, marxistischen Verständnis des „titanischen Strebens“ Fausts als literarisches Abbild der prozesshaft-dialektischen, perfektibilistischen Geschichtsbewegung, die auf das Ziel der absoluten innerweltlichen Emanzipation zuläuft, in der der Mensch zum Herr der Schöpfung wird und alles aus eigenem Willen macht, auch sich selbst, wie es Prometheus verkündet und der Faustschüler Dr. Wagner im Laboratorium ausprobiert, im Unterschied also zu dieser modernen Utopie des zielgerichteten Produktionsprozesses liest Wilhelm Goethes Faust als Menschheitsdrama, das eine Kreisbewegung ausführt (vgl. WFK, 2). Wie in der biblischen Geschichte vom „verlorenen Sohn“ - auf höchst unorthodoxe Weise arbeitet der promovierte evangelische Theologe Wilhelm mit Bibelbezügen - handle die Tragödie Fausts vom Verlust eines wertvollen Gutes, das am Ende wiedergefunden werde (vgl. WFK, 48). Dabei ist es in der interreligiösen Perspektive Wilhelms gleichgültig, zumal Anfang der 1920er Jahre an der Peking Universität, ob das wertvolle Gute, das man als Bezugspunkt verlieren und wiederfinden kann, wie im Prolog und Epilog von Goethes Text der „Herr“, das auf ihn zurückgehende „grosse göttliche Weltgesetz“ oder das „Ewig-Weibliche“ oder Gott oder Dao oder Natur heißt (WFK, 11-12). Entscheidend ist der Gedanke, dass es für alles menschliche Handeln einen unhintergehbaren Rahmen und Bezugspunkt gibt „sub specie aeternitatis“ (WFK, 11) oder - wie man ergänzen darf - „sub specie naturae“. Ausdrücklich betont Wilhelm die metaphysische Einfassung des großen Weltspiels, die alle menschlichen Perspektiven immer schon umgreift. Entsprechend deutlich tritt in seiner Perspektive die Erlösungsbedürftigkeit der Willenshelden Prometheus und Faust in den Blick, obgleich sie doch die Selbsterlösung des Menschengeschlechts durch „titanisches Streben“, also durch Arbeit und Produktion proklamieren (WFK, 41-42).

Nicht das „titanische Streben“ Fausts nämlich, so die Pointe von Wilhelms Faust-Kommentar, sondern die meditative Beruhigung des vom prometheischen Willen angetriebenen Geschehens gewährt dem ungeduldigen Protagonisten die ersehnte Glückserfahrung der harmonischen Übereinstimmung von Selbst und Welt. Exemplarisch zum Ausdruck komme der Moment des erfüllten 
Daseins in dem von Faust in der Szene „Wald und Höhle“ gesprochenen „Dankgebet“ (WFK, 66), das dann bereits auf die Versöhnungsszenerie am Ende von Faust II und auf die Mystik des „Ewig-Weiblichen“ vorausweise, sei es doch erst die Begegnung mit Margarete, die Faust zur Kontemplation der Natur und der Einheit von Selbst und Welt befähige und ihn erkennen lasse, dass „sich der Kreis des Zusammenhanges schliesst. So ist Faust durch das Erleben einer sein ganzes Wesen durchdringenden Liebe dem Ziele nahegekommen, das seinem einsamen titanischen Streben, und wenn es auch noch so wild sich gebärdete, ewig fremd war. Damit hat er das Höchste erreicht, was dem Menschen vergönnt ist“ (WFK, 67-68). Unter dem Regiment des „titanischen Strebens“, das von Mephisto im nächsten Augenblick sogleich wieder angestachelt werde, bleibe Faust im weiteren Fortgang des Dramas jedoch vom Glück des erfüllten Lebens notwendigerweise ausgeschlossen.

Diesen Glücks- und Unglückshorizont der Faustdeutung muss man im Auge behalten, wenn man auf das berühmte Schlusskapitel „Ost und West“ in Wilhelms Rückblick auf seine Lebensepoche in China zwischen 1899 und 1924 schaut, in dem er dem prometheisch-faustischen „titanischen Streben“ des Westens die Kontemplationsschulen des Ostens, das Ordnungsdenken des Konfuzianismus und die Mystik des Daoismus, gegenüberstellt:

Die Ordnung der chinesischen Gesellschaft beruht darauf, daß jeder seinen natürlichen, ihm zukommenden Platz hat, von dem aus er sich voll betätigen kann und über den hinauszugehen weder recht noch erwünscht ist. So hat im chinesischen Weltbild der titanische Stolz keine Stelle, denn da niemand dem Menschen seinen Platz streitig macht, ist es nicht heroisch, sondern verbrecherisch, darüber hinaus zu wollen. [. . .] Das Untitanische der chinesischen Weltanschauung im Gegensatz z. B. zur deutschen drückt sich sehr gut darin aus, daß das Unrechte bei uns ein „Fehler“ ist, in China ein „Überschreiten“. Auch den himmlischen Mächten gegenüber findet sich kein titanisches Aufbäumen: denn man sieht sich nicht einem persönlichen Autokraten gegenüber, der die Welt mit Willkür und Ungerechtigkeit lenkt [wie Prometheus es Zeus vorwirft], sondern der tiefste Weltsinn ist überpersönlich. Gegen ihn kann es keine Auflehnung geben, da er ja nicht etwas Fremdes ist, sondern mit den eigenen Tiefen des Menschen wesentlich eins.

(Wilhelm 1980, 429-430)

Eingedenk solcher Beobachtungen Wilhelms gewinnt man eine Ahnung von den ungeheuren Dimensionen des revolutionären Bruchs in Chinas Geschichte des 20. Jahrhunderts, da sich nun offensichtlich auch im Osten Faust und Prometheus daran machten, „titanisch“ zu agieren.

Über die singuläre, eminent wirkmächtige Position, die Wilhelm - nicht zuletzt aufgrund der thematischen Verbindung von China und Goethe - während 
des die 4.-Mai-Bewegung begleitenden Disputs zwischen Modernisierern und Hütern der Tradition einnahm, heißt es zusammenfassend bei Wolfgang Bauer:

Der Beginn der zwanziger Jahre war für China eine der politisch konfusesten, zugleich aber [. . . ] fruchtbarsten Epochen, die es verständlich macht, daß die „Literarische Revolution“ [der 4.-Mai-Bewegung] sich fast mehr in das Gedächtnis der damals jungen Generation, zu der auch Mao Tse-tung gehörte, eingeprägt hat, als die Revolution von 1911, die den Sturz des Mandschu-Kaiserhauses und die Errichtung der Republik nach sich zog. Das Wirken Richard Wilhelms (1873-1930), der auf eine unnachahmliche, heute kaum mehr vorstellbare Weise eine Brücke zwischen China und Deutschland zu schlagen suchte, brachte diese Ansätze während einer kurzen, aber sehr intensiv erlebten Zeit zu voller Blüte.

(Bauer 1972, 190)

\section{Fazit mit Goethe und Marx: Weltinterpretation und Weltveränderung}

Blicken wir vor diesem historischen Hintergrund des 4. Mai 1919 auf Guo Moruos und auf Richard Wilhelms Parallelunternehmungen unter der Überschrift „Goethe und China“ zurück, können wir zusammenfassend feststellen: Dienen Guo Moruo Faustübersetzung und Faustdeutung dazu, den Nachweis einer Übersetzbarkeit auch der modernen Revolution in chinesische Verhältnisse zu führen und dadurch die Revolution in China zu befördern, so bezieht sich Richard Wilhelm zur gleichen Zeit am gleichen Ort desgleichen auf Goethe und auf Goethes Faust, um die Klassiker der chinesischen Philosophie zu erläutern und um solchermaßen die Übersetzbarkeit und mithin die Universalität der Kontemplationsexerzitien Chinas zu demonstrieren. Angesichts der in den 1920er Jahren rasant anhebenden chinesischen Marx-Rezeption liegt es dann nahe, die paradox verlaufenden Übersetzungstätigkeiten Guos und Wilhelms auf jenen Widerspruch zwischen Kontemplation und Aktion zu beziehen, in dem Marx - in der elften Feuerbachthese - gleichsam den Beginn des globalen Revolutionszeitalters der Moderne ausgerufen hat. In ihren einander gegenüberstehenden Plädoyers für Weltinterpretation (Theorie) und für Weltveränderung (Praxis) können sich Wilhelm und Guo beide gleichermaßen auf Goethes Weltgedicht Faust über die tragische Kollision von Tradition und Moderne berufen, lassen sich doch aus diesem Text die Lebenslehren sowohl der Vita contemplativa - „Am Anfang war das Wort“! respektive Logos und Dao wie auch der Vita activa - „Am Anfang war die Tat!“ - zitieren. ${ }^{24}$

24 Einem persönlichen Kontakt jedoch scheinen Guo und Wilhelm während dessen über beinahe fünfundzwanzig Jahre andauerndem China-Aufenthalt (1899-1920 und 1922-1924) konsequent 
Guo Moruo sieht Goethes Faust mit guten philosophischen Gründen unter Berufung auf Hegel und Marx als Repräsentanten des „revolutionären Bruchs im Denkens des 19. Jahrhunderts“ in Europa an, ${ }^{25}$ den er als prometheische Vorbildfigur ins chinesische 20. Jahrhundert versetzt. Hinter den von Faust vollzogenen Bruch mit der Überlieferung führt kein Weg zurück in die alte Welt, die Brücken sind abgebrochen, Vermittlung und Kompromiss sind ausgeschlossen.

Sicherlich nicht den Weg zurück in die alte Welt, aber doch die Möglichkeit einer Vermittlung zwischen Tradition und Moderne eröffnet Wilhelm in seiner Auslegung derselben Fausttragödie, insofern er die Aufmerksamkeit auf die tragödienimmanente Kritik des „titanischen Strebens“ lenkt und, damit einhergehend, auf Goethes Nähe sowohl zur konfuzianischen Ordnungsphilosophie und wie auch zur daoistischen Mystik. Richard Wilhelm baut also die Brücke wieder auf, die den Überlieferungszusammenhang auch in den Umbruchzeiten der modernen Vita activa bewahrt und über die ein verlorener Sohn zurückkehren könnte. ${ }^{26}$

aus dem Wege gegangen zu sein. Sehr befremdlich wirkt diese Kommunikationsvermeidung angesichts des gemeinsamen Goetheinteresses im Kontext des politischen Umbruchs in China. Wolfgang Bauer bemerkt dazu 1973 im Vorwort zu ausgewählten Aufsätzen Wilhelms: „Um so merkwürdiger freilich ist es auch, daß er [Richard Wilhelm] zu dem fruchtbarsten Übersetzer von Goethes Werk, dem Gelehrten Kuo Mo-jo (geb. 1892) [d. i. Guo Moruo], der heute noch als Präsident der Akademie der Wissenschaften eine hervorragende Stellung im Geistesleben Chinas einnimmt, nicht in Kontakt trat. Gerade die Tatsache, daß Kuo Mo-jo sich schon sehr bald der Kommunistischen Partei anschloß, hätte Richard Wilhelm wohl zu einer eingehenderen Auseinandersetzung mit dem chinesischen Kommunismus bewegen können, zu der es niemals kam.“ Und über das mögliche Motiv von Wilhelms Verhalten fügt Bauer hinzu: „Es ist aber nicht weniger denkbar, daß er bewußt seine Aufgabe allein darin sah, das vergehende Alte China in bestimmten Teilen auf Europa umzupflanzen, um seine Werte nicht nur für den Westen zu gewinnen, sondern letztlich auch für China selbst zu erhalten“ (Bauer 1973, 26). - Sicherlich, darf man hinzufügen, war es gerade Guos Hinwendung zur Kommunistischen Partei, die Wilhelm auf Distanz gehen ließ. Wilhelm nämlich hatte sich nach der Abdankung der Mandschu-Dynastie und nach Gründung der chinesischen Republik jener Gruppe unter den führenden Initiatoren der 4.-Mai-Bewegung angeschlossen, die sich wie Cai Yuanpei und Hu Shi eben nicht auf den Weg in den Kommunismus machten. Dem 1926 erschienenen autobiografischen Rückblick auf seine China-Erfahrungen hat Richard Wilhelm denn auch die Widmung vorangestellt: „Herrn Tsai Yüan Pei, dem Kämpfer für Recht und Freiheit, dem Gelehrten, dem Freund“ (Wilhelm 1980, 26).

25 Um den Untertitel von Karl Löwiths berühmter Ideengeschichte des 19. Jahrhunderts zu zitieren (Löwith 1988 [1941]).

26 Wilhelm hat sich offenbar in der unzeitgemäß-paradoxen Rolle eines europäischen Hüters der chinesischen Tradition gesehen, den die Ironie der Geschichte im Augenblick des Zusammenbruchs eben dieser Überlieferung nach China versetzt hatte. Bezeichnenderweise in der Einleitung zur 2. Auflage seiner Konfuzius-Übersetzung bemerkt er 1914 über seine anachronistische deutsch-chinesische Position: „Die hohe Verehrung, die Kung [Konfuzius] durch die Mandschu-Dynastie gezollt wurde und die soweit ging, daß er beim großen Opfer als Genosse 
Solchermaßen entwerfen Guo Moruo und Richard Wilhelm im Umfeld des 4. Mai 1919 und mithin am Beginn des chinesischen Revolutionsjahrhunderts zwei Möglichkeiten der Faustdeutung, die zugleich zwei Möglichkeiten der Geschichtsdeutung darstellen: Liest Guo Moruo das Faust- resp. Menschheitsdrama als Prozess, den die Gegenwart gegen die Vergangenheit anstrengt, um die Bewegung in eine befreiende Zukunft $\mathrm{zu}$ beschleunigen, so erläutert Richard Wilhelm Goethes Text als literarisches Abbild eines Vermittlungsgeschehens, das einen versöhnenden Ausgleich zwischen Tradition und Moderne zulässt. Im Rückblick von heute gewinnt man den Eindruck, dass das gewaltige Gesellschaftsdrama des chinesischen 20. Jahrhunderts in seinen verschiedenen Epochen dann in der Tat zwischen diesen beiden Möglichkeiten des revolutionären Prozessdenkens und der versöhnenden Vermittlungsoperation schwankte. ${ }^{27}$

des höchsten Gottes verehrt wurde, hat nun neuerdings eine schwere Gefahr für ihn gebracht. Mit der Mandschu-Dynastie [bei ihrer Abdankung 1911] brach auch die Verehrung Kungs in Trümmer. Sein Tempel verfällt. Keine Opfer werden ihm mehr gebracht. Die Literaten haben sich zum Teil anderen Idealen zugewandt, zum Teil stehen sie einflußlos abseits. Es scheint, als sei für den Konfuzianismus wieder eine ähnlich gefährliche Zeit angebrochen wie die des Tsin Schi Huang. Ja, gewissermaßen ist heute die Gefahr noch größer. Denn was zusammengebrochen ist, ist nicht wie damals nur ein Glied im großen Zusammenhang, vielmehr sind die gesamten Grundlagen erschüttert. Der Fürst ist beseitigt und damit die notwendige Form des konfuzianischen Staates. Denn man mag sagen, was man will: auf die Republik läßt sich die konfuzianische Staatslehre nicht aufpropfen. Aber die Auflösung geht weiter. Die gesellschaftliche Struktur kommt ins Wanken. Die Familie, in der die wichtigsten Beziehungen der konfuzianischen Lehre wurzeln, ist in einer radikalen Umgestaltung individualistischer Art begriffen. [. . . ] Wird Kungs System die Wirren des heutigen Tags überdauern? Oder wird es untergehen in der Umwandlung der alten chinesischen Welt? Für alle Fälle ist es der Mühe wert, diesen Versuch der Menschheitsorganisation zu retten zu einer Zeit, da unmittelbare Anschauung seine Kenntnis noch ermöglicht; denn es handelt sich um eine der wichtigsten Erscheinungen der Menschheitsgeschichte“ (Wilhelm 2018 [1910], 61-62).

27 Hartmut Eggert danke ich für wichtige Hinweise und inspirierende Gespräche zum chinesisch-deutschen Themenfeld. - Der vorliegende Beitrag sowie der einleitende Essay entstanden während eines Fellowships, das mir dankenswerterweise von der Carl Friedrich von Siemens Stiftung in München gewährt wurde. 


\section{Literaturverzeichnis}

Bartels, Nora. „Goethes ,Faust‘ bei Mori Rintarō und Guo Moruo. Vorstudien zum Verständnis ihrer Übersetzungen“. Japonica Humboldtiana 15 (2012): 77-150.

Bauer, Wolfgang. Geschichte der chinesischen Philosophie. Hrsg. Hans van Ess. München 2006.

Bauer, Wolfgang. China und die Hoffnung auf Glück. Paradiese, Utopien, Idealvorstellung in der Geistesgeschichte Chinas. München 1974.

Bauer, Wolfgang. „Einleitung “. Richard Wilhelm: Botschafter zweier Welten. Auswahl und Einleitung von Wolfgang Bauer. Düsseldorf und Köln 1973. 6-38.

Bauer, Wolfgang. „Goethe und China: Verständnis und Missverständnis“. Goethe und die Tradition. Hrsg. Hans Reiss. Frankfurt am Main 1972, 177-197.

Chen, Xiaoming. From the May Fourth Movement to Communist Revolution. Guo Moruo and the Chinese Path to Communism. Albany 2007.

Dabringhaus, Sabine. Mao Zedong. München 2008.

Debon, Günter. „Goethes Berührungen mit China“. Goethe-Jahrbuch 117 (2000): 46-55.

Dschuang Dsi. Das wahre Buch vom südlichen Blütenland. Aus dem Chinesischen übersetzt und erläutert von Richard Wilhelm. München 2008 [urspr. Jena 1912].

Franke, Wolfgang. Chinas kulturelle Revolution. Die Bewegung vom 4. Mai 1919. München 1957.

Goethe, Johann Wolfgang. Faust. Hrsg. Albrecht Schöne. Berlin 2017.

Goethe, Johann Wolfgang. „Chinesisch-deutsche Jahres- und Tageszeiten“ [1827]. Johann Wolfgang Goethe. Sämtliche Werke (Münchner Ausgabe). Hrsg. Karl Richter. Band 18.1. München 2006a, 16-20.

Goethe, Johann Wolfgang. „Zur Morphologie, I 2“ [urspr. 1820]. Johann Wolfgang Goethe. Sämtliche Werke (Münchner Ausgabe). Hrsg. Karl Richter. Band 12. München 2006b, 100.

Goethe, Johann Wolfgang. „Prometheus“ [urspr. 1773/1774]. Johann Wolfang Goethe. Sämtliche Werke (Münchner Ausgabe). Hrsg. Karl Richter. Band 1.1. München 2006c. 229-230.

Goethe, Johann Wolfgang. „Gott und Welt“ [urspr. 1827]. Johann Wolfang Goethe. Sämtliche Werke (Münchner Ausgabe). Hrsg. Karl Richter. Band 13.1. München 2006d. 150-155.

Gu, Xuewu. Konfuzius zur Einführung. Hamburg 1999.

Guo, Moruo. „Himmelshund“. Nachrichten von der Hauptstadt der Sonne. Moderne chinesische Lyrik. 1919-1984. Hrsg. und aus dem Chinesischen übersetzt von Wolfgang Kubin. Frankfurt am Main 1985a.

Guo, Moruo. Jugend. Autobiographie. Zweiter Band. Übertragen aus dem Chinesischen und Nachwort von Ingo Schäfer. Frankfurt am Main 1985b.

Hsia, Adrian. China-Bilder in der europäischen Literatur. Würzburg 2010.

I Ging. Das Buch der Wandlungen. Aus dem Chinesischen übertragen und erläutert von Richard Wilhelm. Köln 1986 [urspr. Jena 1924].

Konfuzius. Gespräche. Aus dem Chinesischen übersetzt und erläutert von Richard Wilhelm. Köln 2018 [urspr. Jena 1910].

Laotse. Das Buch des alten Meisters vom Sinn und Leben. Aus dem Chinesischen übersetzt und erläutert von Richard Wilhelm. Köln 2019 [urspr. Jena 1911].

Löwith, Karl. „Von Hegel zu Nietzsche. Der revolutionäre Bruch im Denken des 19. Jahrhunderts“ [urspr. 1941]. Sämtliche Werke. Band 4. Karl Löwith. Stuttgart 1988. 
Löwith, Karl. „Weltgeschichte und Heilsgeschehen. Die theologischen Voraussetzungen der Geschichtsphilosophie“ [urspr. 1949]. Sämtliche Schriften. Band 2. Karl Löwith. Stuttgart 1983.

Lukács, Georg. „Fauststudien“. Goethe und seine Zeit. Georg Lukács. Bern 1947, 127-207. Penzler, Johannes (Hrsg.). Die Reden Kaiser Wilhelms II. Band 2 (1896-1900). Leipzig 1904. Roy, David Tod. Kuo Mo-jo. The Early Years. Cambridge, MA 1971.

Schäfer, Ingo. „Über das Interesse eines chinesischen Dichterhelden an einem deutschen Dichterfürsten. Anmerkungen zur Bedeutung Goethes für Guo Moruos Zyklus ,Göttinnen““. Zeitschrift für Kulturaustausch 36 (1986): 382-386.

Schmidt-Glintzer, Helwig. Kleine Geschichte Chinas. München 2008.

Schmidt-Glintzer, Helwig. „Konfuzius - Gemeinschaftskunst im alten China“. Ma'at Konfuzius Goethe. Drei Lehren für das richtige Leben. Jan Assmann, Helwig Schmidt-Glintzer und Ekkehart Krippendorff. Frankfurt am Main 2006. 71-100.

Wang, Pu. The Translatability of Revolution. Guo Moruo and Twentieth-Century Chinese Culture. Cambridge, MA und London 2018.

Wilhelm, Richard. „Einleitung“. Gespräche. Konfuzius. Aus dem Chinesischen übersetzt und erläutert von Richard Wilhelm. Köln 2018 [urspr. Jena 1910]. 25-66.

Wilhelm, Richard. Die Seele Chinas. Mit einem Vorwort von Wolfgang Bauer. Frankfurt am Main 1980.

Wilhelm, Richard. „Goethe und die chinesische Kultur“. Jahrbuch des Freien Deutschen Hochstifts 1927. Frankfurt am Main 1927. 301-316.

Wilhelm, Richard. Kommentar zu Goethes Faust von Dr. Richard Wilhelm. Vorlesungsmanuskript, eingesehen in der Bibliothek der Peking Universität. Peking o. J. (zitiert als „Wilhelm: Faust-Kommentar“ bzw. „WFK“).

Yang, Wuneng. Goethe in China (1889-1989). Frankfurt am Main 2000.

\section{Bildquellen}

Abbildungen 1, 2, 3, 4, 6, 7, 8 Abbildung 5
Bildarchiv von Michael Jaeger

Wikipedia 